\title{
Development of novel-engineering-based maker education instructional model
}

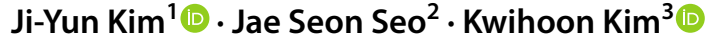

Received: 10 August 2021 / Accepted: 29 November 2021 / Published online: 9 February 2022

(C) The Author(s), under exclusive licence to Springer Science+Business Media, LLC, part of Springer Nature 2022

\begin{abstract}
Attaining equitable education for all is one of the sustainable development goals. Not only the gap of education between urban and rural students but also the gap of access to information and communications technology also exists. Thus, an effort to resolve this gap is necessary. This study combines novel engineering, which is the fusion of engineering and literacy educational methods with maker education, to create a sustainable model of maker education. Through this process, an instructional model for a novel engineering-based maker education is proposed that would enable the utilization of the model in rural elementary school environment. To achieve this, this study analyzed the literature regarding maker education, novel engineering, and design thinking to develop, draft, and verify internal validity through an expert's review and usability evaluation. In addition, this study includes an example class for rural elementary students with application of the model to verify the model's external validity and confirm that the model significantly improved the maker mindset. Finally, this study proposes final instructional model by modifying and improving the draft based on the recommendations derived from the validity verification process. The proposed instructional model was developed as a suitable form for rural school students, which can use low-cost teaching tools to lower the entry barrier to information and communications technology education. The model process developed in this study has the advantage of raising convergence problem-solving abilities and the maker mindset, in terms of a making project that fuses literature and engineering, among students.
\end{abstract}

Keywords Maker $\cdot$ Novel engineering $\cdot$ Design thinking $\cdot$ STEM $\cdot$ Engineering education $\cdot$ Literacy integration

Kwihoon Kim

kimkh@knue.ac.kr

Extended author information available on the last page of the article 


\section{Introduction}

The sustainable development goals (SDGs) adopted by the United Nations (UN) in 2015 are 17 goals that are hoped to be accomplished by 2030 through international cooperation (United Nations, 2015). Among them, SDG 4, which is related to education, aims to attain equitable educational opportunity for all without discrimination according to the external environment (United Nations, 2015). Achieving the SDG 4 is a difficult task for all nations (Niens et al., 2020), but it is recommended that UN member states work toward achieving it, as they do toward the other SDGs (United Nations, 2015). Discrimination due to external environments discussed in SDG 4 also includes a geographical factor. Ultimately, resolving a gap of education between urban and rural areas is an essential element in achieving SDG 4. Accordingly, the United Nations Educational, Scientific and Cultural Organization (UNESCO) proposed the learning objectives for Education for Sustainable Development (ESD) and dealt with education in rural areas as one of the cognitive learning objectives in SDG 4 (UNESCO, 2017).

In particular, information and communications technology (ICT) accessibility is one of the issues that is dealt with in relation to the educational gap between urban and rural areas (Ainley, 2006; Chandra et al., 2021; Kim et al., 2014; Lembani et al., 2020; Liao \& Chang, 2010; Umar \& Jalil, 2012). Although the ICT-related content is considered an essential subject to the emergence of the Fourth Industrial Revolution era, ICT literacy among students in rural areas is reportedly still lower than among urban students (Ainley, 2006; Kim et al., 2014; Liao \& Chang, 2010; Umar \& Jalil, 2012). Distance learning, which was suddenly employed due to the COVID19 pandemic, further revealed the educational gap between urban and rural areas. This was because the penetration rate of the internet and availability of household computers for rural students was lower than that for urban students, which meant the basic infrastructure to participate in remote education was not adequately provided (Chandra et al., 2021; Lembani et al., 2020). In this background, the equal learning opportunity including the use of ICT is discussed as one of the topics in SDG 4 (UNESCO, 2017). Although rural areas lack the ICT infrastructure, ICT education is essential to children who will lead our future, and it is necessary to actively promote ICT education for rural schools. Thus, this study aims to introduce maker education as one a potential ICT education method for rural areas and accordingly proposes continuous research and policies for ICT education in rural areas.

\subsection{Maker education}

Much attention has been paid to convergence education and competency education as the future education keywords in this advanced society known as the Fourth Industrial Revolution. Maker education is one of the suitable educational methods for convergence and competency educations (Blikstein, 2013; Kim, 2018; Kim et al., 2020; Marshall \& Harron, 2018; Martin, 2015; Seo \& Lee, 2018). From the convergence education viewpoint, maker education is a form of project-based learning that 
addresses a problematic context in real life by offering a solution to the problem. Thus, because the converged knowledge of various subjects is used in the problemsolving process, maker education is considered one of the convergence educational methods (Blikstein, 2013; Marshall \& Harron, 2018). From the competence education viewpoint, maker education is viewed as a way to raise future competence (Seo \& Lee, 2018). This is because students participate in making activities and develop the maker mindset through maker education (Martin, 2015). The maker mindset is related to competencies that are seen as important in recent years such as innovative ideas and action (Kang, 2017), critical thinking, creativity, problem solving, and collaboration (Kang \& Yoon, 2017a), all of which spotlight maker education as the most efficient method of competence education.

Despite the above-mentioned advantages, maker education has some concerns attached to it. One of the concerns is that maker education may be an unsustainable, one-off education in the school environment (Blikstein, 2013; Kim, 2018). If maker education is a one-off event, this may indicate that it focuses on the result rather than the process (Blikstein, 2013), and while learners may be interested temporarily, the educational model may have a negative impact on the cyclic and repetitive nature of making activities, maker mindset internalization, and the expansion of maker culture, etc. (Kim, 2018). Thus, maker education should be conducted as a sustainable education rather than a simple experience-oriented education. This study aims to combine novel engineering (NE), an educational method that fuses literary and engineering education, with maker education for a sustainable maker education method.

\subsection{Novel engineering}

$\mathrm{NE}$ is a fusion of education methods to find engineering solutions from a literary work (Milto et al., 2020; Novel Engineering, n.d.). This is directly related to the 3 Rs (reading, writing, and arithmetic), which refers to the traditional basic learning skills - NE is thus an essential and sustainable subject matter to be taught in schools, as it can improve the sustainability that is currently lacking in the maker educational method (Kim \& Lee, 2020). In addition, NE can be a means of achieving a sustainable maker educational model because it can fulfill the lack of systematic steps in the problem-solving method, which has been pointed out as a relative deficiency in maker education (Yoon, 2018). Moreover, it can raise the student's understanding of maker education and it can be applied in an integrative manner to various subjects according to the assigned book's contents (Kim et al., 2020).

\subsection{Design Thinking}

Although maker education is an education paradigm with many possibilities, it is considered to be lacking the systematic steps of a problem-solving method, consideration of standpoints on problem-solving targets, and detailed observation emphasis in a relative sense (Yoon, 2018). To overcome these drawbacks, several studies employed design thinking as the methodology of maker education (Bowler, 2014; 
Flores, 2016; Institute of Design at Stanford, n.d.; Kim, 2018; Lembcke et al., 2018; O’brien, 2016; Roffey et al., 2016; Smith et al., 2015; Yoon, 2018).

Design thinking refers to the process by which designers solve problems (IDEO Design Thinking, n.d.; The Interaction Design Foundation, n.d.; Roffey et al., 2016). In modern society, design thinking is not simply limited to product design but can be applied to all areas of society from a wide range of viewpoints (IDEO Design Thinking, n.d.). In design thinking, problems are reconfigured according to a human-centered approach, and designers focus on user's needs (IDEO Design Thinking, n.d.; Riverdale \& IDEO, 2014; The Interaction Design Foundation, n.d.). Design thinking based on empathy has been actively used for creative problem solving in many areas, including management, marketing, business, etc. (Kim, 2018; The Interaction Design Foundation, n.d.).

With this background in mind, this study aims to develop a novel-engineeringbased maker education (NE-Maker) instructional model which is available in elementary schools in rural areas. To this end, the study undertakes a review of prior studies, develops a draft of the model, and offers confirming and improvement processes to propose a final NE-Maker instructional model for sustainable maker education.

\section{Related works}

\subsection{Maker education}

Maker education is an educational paradigm which is based on experientialism, constructivism, and constructionism, derived from the maker movement for manufacturing (Kang, 2017; Martin, 2015). The maker movement refers to the trend that deals with the question "how to make" by empowering makers who create what they need (Hatch, 2014) or the trend that is defined by putting the creative making process into practice in daily life and cultivates the maker's own experiences and knowledge (Dougherty, 2012; Martin, 2015). As one of the small-quantity batchproduction systems considered appropriate for manufacturing in the 4th Industrial Revolution, much attention has been paid to the maker movement. Thus, policies for the maker movement have been supported at the national level not only in the U.S. but also in Europe and China (The White House Office of the Press Secretary, 2015; Fried \& Wetstone, 2014; Lee et al., 2019).

The educational value found in Maker Faires of the maker movement and the program operation of makerspaces has been recognized as being consistent with existing educational theories, and the form that has been established as an educational paradigm is maker education (Dougherty, 2013; Kang \& Yoon, 2017b; Kang, 2017). Maker education is most related to constructionism that emphasizes learningby-making among educational theories (Kim, 2018; Kim et al., 2020; Martinez \& Stager, 2013; Papert \& Harel, 1991; Yoon, 2018). Learning-by-making is a concept that emphasizes the meaning of making more than Dewey's concept of learningby-doing; the latter indicates that creating meaningful products or social outcomes is the most effective learning experience (Ackermann, 2001; Kang \& Yoon, 2017a; 
Papert, 2000; Papert \& Harel, 1991; Yoon, 2018). Because maker education constructs and systematizes knowledge and experience in the process where learners produce deliverables and share experiences, it is closely related to the learning principle of constructionism (Kim, 2018; Kim et al., 2020; Martinez \& Stager, 2013; Papert \& Harel, 1991; Stager, 2006; Yoon, 2018).

Several frameworks have been proposed to apply maker education to the education field. The maker-centered learning framework proposed by Agency by design (n.d.) emphasized the importance of observation and focused on the development process. In particular, it stressed that the maker mindset was affected by a sensitivity to design. The tinkering learning dimensions (TLD) framework proposed by Bevan et al. (2015) emphasized tinkering, which leads to a discovery of possibility through the open exploration of materials. Free tinkering is the basis of the following making activities (Maker Ed, 2015): 5 ONs (Minds-on, Hands-on, Hearts-on, Social-on, and Acts-on) of Yoon (2018) were proposed including Social-on, which emphasized sharing, cooperation, and communication, etc. reflecting the maker activity characteristics, and Acts-on, which stressed the social practice, to 3 ONs (Minds-on, Hands-on, and Hearts-on), which reflect the $3 \mathrm{Hs}$ (Head, Heart, Hand) of Pestalozzi. This stressed the holistic aspect of maker education. Making in the STEM education framework proposed by Marshall and Harron (2018) emphasized the convergence aspects of maker education. In contrast with the maker-centered learning framework, which was focused on the development process itself (Clapp et al., 2016; Clapp et al., 2020; Agency by design, n.d.), the making in STEM education framework emphasized making itself and the maker mindset. In addition, while the TLD framework is suitable for free tinkering (Bevan et al., 2015), Marshall and Harron (2018) is suitable for open-ended problem-based learning. Table 1 summarizes the frameworks of maker education.

After reviewing the prior studies on maker education frameworks, the derived implications are as follows: first, the educational viewpoint should be clearly delineated. Maker education is a concept that draws the maker movement within the education domain, an activity traditionally outside of that domain (Kang \& Yoon, 2017b; Kang, 2017). As a result, components vary according to viewpoint and criteria (Bevan et al., 2015; Agency by design, n.d.; Kim, 2019; Yoon, 2018). Because the form and flow of maker education vary according to the lens through which maker education is analyzed, it is very important to set up a clear educational perspective.

Second, the importance of collaboration and sharing should be stressed. Both collaboration and sharing have been emphasized as the core of the maker movement (Cohen et al., 2017; Hatch, 2014) and have been proposed as components of the maker mindset in previous studies (Bevan et al., 2015; Cohen et al., 2017; Hatch, 2014; Kim \& Lee, 2020; Martin, 2015; Regalla, 2016; Yoon et al., 2019). Thus, it is necessary for students to have an opportunity to fully experience related activities to enhance their collaboration abilities and sharing competency.

Third, the maker mindset should be emphasized. The maker mindset refers to the value, propensity, and belief of makers who participate in making activities, and it is the key part of making activities (Dougherty, 2013; Kim, 2020a; Martin, 2015). It makes maker education different from simple craft education or practice 


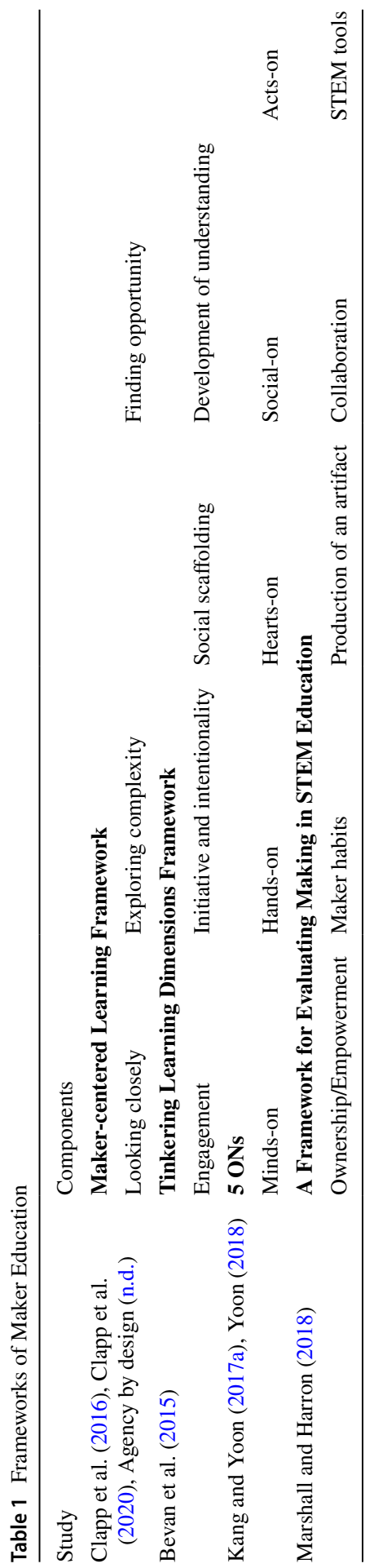


(Kim, 2019). Maker education would fail to draw effects such as innovative ideas and actions (Dougherty, 2012), critical thinking, creativity, problem-solving skills, and collaboration if the maker mindset were to be overlooked and only the program, makerspace, tools, materials, and deliverables, etc. were emphasized (Kapur, 2016). The components of the maker mindset differ slightly depending on the study, as summarized in Table 2.

This study was conducted based on the maker mindset of Kim et al. (2020), whose work reflected the study by Cohen et al. (2018), itself based on Martin (2015), which was cited in most studies as a sub-element of the maker mindset.

\subsection{Novel engineering}

The education model that fuses literacy with other domains is effective at improving achievements in both literacy and other learning domains (Morrow et al., 1997; Palinscar \& Duke, 2004), which lead to various attempts to fuse literacy education with a variety of other subjects such as art (Grant et al., 2008), mathematics (Halladay \& Neumann, 2012), and science (Morrow et al., 1997), etc. In this context, NE was proposed by Tufts University with a grant from the US National Science Foundation as a fusion education of engineering and literacy (Mccormick, 2015; Milto et al., 2016). The official NE website is now being run by the Center for Engineering Education and Outreach (CEEO), which is an affiliated institution of Tufts University where online lectures and workshops for teachers are conducted. In addition, it recommends books suitable to NE and presents NE applied classes and related research deliverables to help teachers incorporate the NE (Novel Engineering, n.d.). Although the definition of NE differs slightly in different research (Mccormick, 2015; Milto et al., 2020; Montgomery \& Madden, 2019; Novel Engineering, n.d.), the present study summarizes them to come to a definition of NE as the fusion learning activity of engineering and literacy that has learners discover and design engineering solutions in the meaningful context that is the content and characters in a story. NE is a problem-based learning method that identifies the content of a problem, or challenge faced by characters, through reading a book. It then solves the problems through an engineering approach. In NE, the characters in the story take the place of a client who requests a solution to a problem, whereas students take the role of an engineering designer who suggests solutions based on the client's request (Kim et al., 2020). The educational advantages of novel engineering are as follows (Novel Engineering, n.d.):

1. Works within ELA (English Language Arts) curriculum;

2. Enhances reading comprehension;

3. Engages all learners;

4. Provides integration of different disciplines;

5. Introduces realistic engineering problems;

6. Builds twenty-first century skills;

7. Meets common core and next generation science standards. 


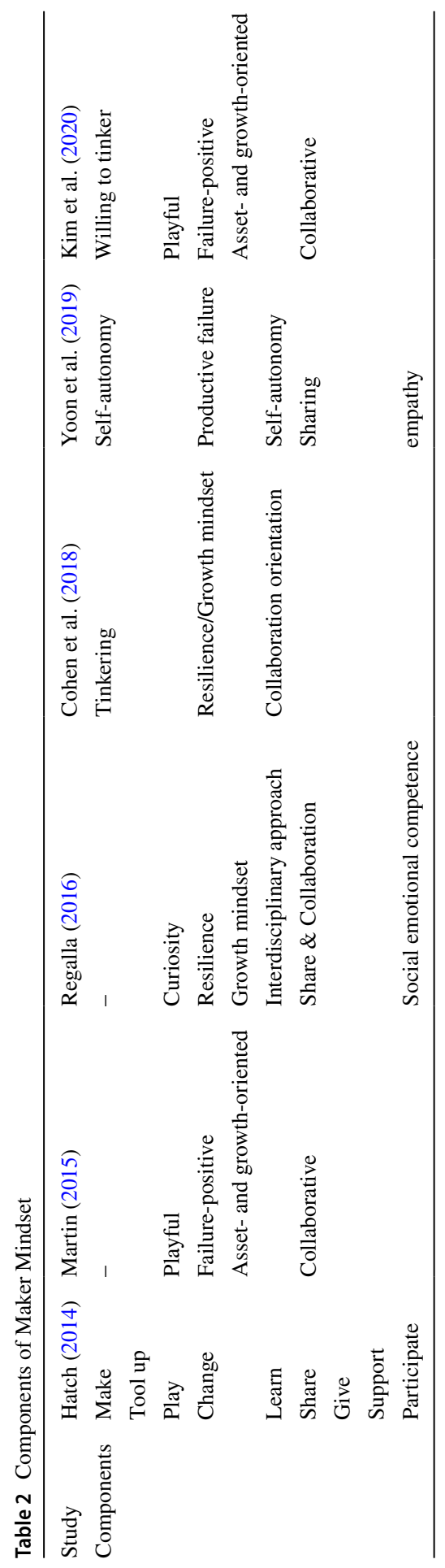


In a study on the educational effectiveness obtained through NE, McCormick (2015) verified that elementary school students could understand and define complex or open-type engineering problems in a class using NE. Kim (2020b) designed and applied a convergence subject NE course with 20 classes for 4th-grade elementary school students and concluded that the class had a significant effect on improving students' reading skills, problem-solving abilities, and engineering creativity. Hong and Cho (2019) designed and applied an NE course with eight classes with the theme 'Anne of Green Gables' for 3rd-grade elementary school students. The result affirmed a positive effect on the interest level, participation, collaboration ability, and communication ability of the learners. Choi (2019) structured and applied three classes where NE was applied with the theme 'The Old Man and The Sea' in the high school 'Automation Equipment' class. The study results verify a positive effect on communication ability, collaboration, problem-solving, and humanities literacy among learners as well benefits for teachers in education skills and expertise. Kim et al. (2020) developed NE-based maker education elective lectures and applied them to undergraduate students with various majors over the semester to demonstrate significant improvements in STEM literacy.

In addition, $\mathrm{NE}$ is expected to be a suitable education method to fuse with various educational paradigms, such as humanities, STEM, computer science education, invention education, and maker education (Choi, 2019; Hong \& Cho, 2019). However, very few studies have been conducted on the concrete effects of NE in combination with other education fields. Thus, it is necessary to verify the education effectiveness of such a fusion (Hong, 2019; Kim, 2020b). Furthermore, there are many studies conducted with elementary school students, but very few studies have been conducted with students of other school levels and more such studies are required (Kim \& Lee, 2020).

The recommended procedure of NE varies slightly in different research projects based on the three steps proposed by Novel Engineering (n.d.). This study subdivided learning activities to derive the learning process of the NE-Maker teaching model. The steps proposed in each study and the subdivided steps in the present study are presented in Table 3 .

There are 12 subdivided steps. The explanation of each step is presented as follows:

1. Selection of book: books that are used in NE are selected;

2. Reading a book: the selected books are read, and the content and story flow are identified;

3. Identifying the problem: the context of the problem faced by the characters is thoroughly analyzed;

4. Reviewing the problem: the constraints, environment, and context in the literary work are identified and the problem to be solved is clarified;

5. Coming up with the solution: as many solutions to the problem as possible are proposed through brainstorming;

6. Designing the solution: the solution is selected under consideration of its achievability and form, such as written text, figures, etc.;

7. Prototyping: a prototype is constructed in order to implement the solution; 


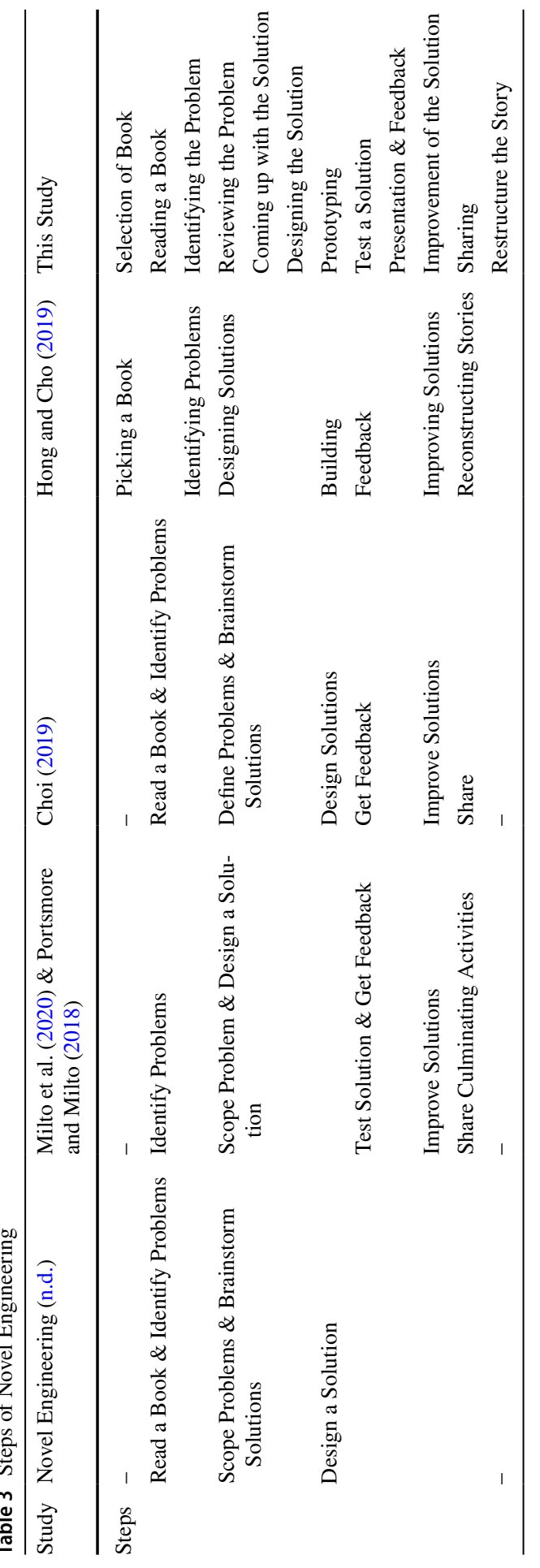


8. Testing the solution: check whether the solution suits the context of the story, and test the performance;

9. Presentation and feedback: present the solution to peers and obtain feedback;

10. Improvement of the solution: based on the feedback, improve the solution;

11. Sharing: the final result is shared with peers;

12. Restructure the story: the story is restructured based on the deliverable content.

Based on the reviewed results from previous studies, the implications of the development of the NE-Maker instructional model are as follows: first, the flow of the NE-Maker instructional model is needed to be flexible, cyclical, and repetitive. This is because the teaching and learning process for solving problems should be as flexible as required rather than following a formalized order as a result of the characteristics of the engineering design process. Furthermore, it should be occasionally cyclical and repetitive (EiE, 2020; Teach Engineering, n.d.; Portsmore, 2010).

Second, the process, rather than the result, should be prioritized by conducting the model as an open-ended project (Agency by design, n.d.; Portsmore \& Milto, 2018). To do this, teachers should create an environment where problems and deliverables are produced diversely. Teachers should act in the role of facilitators in supporting students to conduct a problem-solving project.

Finally, a model that can have a positive impact on both engineering and literacy should be developed. Although NE produces engineering deliverables, the in-depth reading experience is also a very important element, as NE was applied to English Language Arts classes from the outset (McCormick, 2015; Montgomery \& Madden, 2019; Novel Engineering, n.d.). Thus, the NE-Maker instructional model is emphasized to facilitate an in-depth reading through the continuous interaction of engineering solutions with literary work throughout the entire problem-solving process.

\subsection{Design Thinking}

In maker education, the activities of searching for real-world problems, identifying the requirements for solutions, and producing creative solutions are conducted iteratively. This process has a lot in common with design thinking. Thus, studies on the application of design thinking show it to be an activity process and a component of maker education (Bowler, 2014; Flores, 2016; Institute of Design at Stanford, 2020; Kim, 2018; Lembcke et al., 2018; O’brien, 2016; Roffey et al., 2016; Smith et al., 2015; Yoon, 2018). Although the design thinking process is presented slightly differently, it shares a repetitive and organic flow in common with maker education. In addition, it emphasizes human-centered thinking and empathy and repeatedly displays divergent and convergent thinking. The design thinking process proposed in the previous studies, and a summary of them, are presented in Table 4.

The implications of the previous study's analysis in relation to design thinking are as follows: first, it is necessary to emphasize both human thinking and empathy. In this study, NE and design thinking are proposed as methods of maker education. A central commonality between NE and design thinking is that they both can be applied to solving the problems of other people (or fictional characters). In 


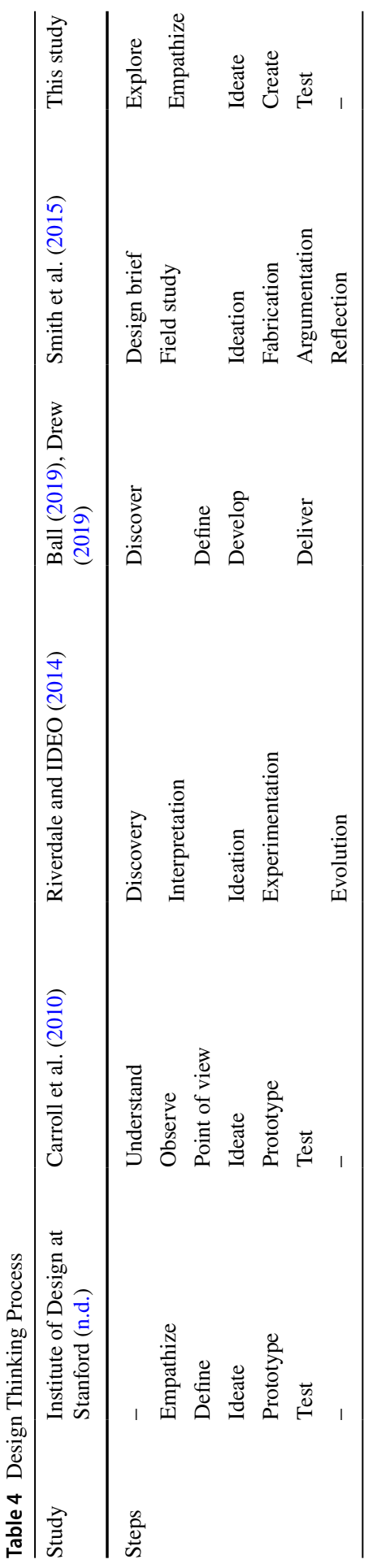


particular, design thinking emphasizes human-centered thinking and empathy during the problem-solving process to make students focus on the user's needs (IDEO Design Thinking, n.d.; Roffey et al., 2016; The Interaction Design Foundation, n.d.). Thus, practicing empathy in NE, as proposed by design thinking, can help one identify the context of the problem and develop a solution.

Second, it is necessary for the structure to properly shift and repeat divergent and convergent modes of thought. In the design thinking process, such shifting and repeating divergent and convergent modes of thought in the problem-solving process are stressed (Drew, 2019; Riverdale \& IDEO, 2014). In particular, since these two modes make a difference in, for example, education promotion techniques and the use of lesson scripts (Riverdale \& IDEO, 2014), when they are applied to education, such changes should be proposed in detail.

$\mathrm{NE}$ and design thinking have a common perspective and goal to produce a deliverable to solve the problem that others face. Thus, similar steps are shared as presented in Tables 3 and 4, and combining their results yields what can be seen in Table 5. "Share" was not a step extracted in the design thinking process through the literature review, but it was an activity that was regarded as important in the maker movement (Anderson, 2012; Dougherty et al., 2016; Hatch, 2014; Kalil, 2013). Thus, it is presented as an additional step in the NE-Maker instructional model.

\section{Methods}

\subsection{Research procedure}

This research has been conducted according to the following procedure: first, a draft of the NE-Maker instructional model was developed through a literature review. Second, a teacher's usability evaluation and validity review were conducted by

Table 5 Relationship between Novel Engineering and Design Thinking Process

\begin{tabular}{lllllll}
\hline $\begin{array}{l}\text { Design thinking } \\
\text { Novel Engineering }\end{array}$ & Explore & Empathize & Ideate & Create & Test & Share \\
\hline $\begin{array}{l}\text { Selection of book } \\
\text { Reading a book }\end{array}$ & 0 & & & & \\
$\begin{array}{l}\text { Identifying the problem } \\
\text { Reviewing the problem }\end{array}$ & 0 & 0 & 0 & & & \\
Coming up with the solution & & & 0 & & \\
Designing the solution & & 0 & 0 & & \\
Prototyping & & & 0 & & \\
Test a solution & & & & 0 & 0 \\
Presentation \& feedback & & & 0 & & \\
Improvement of the solution & & & & & 0 \\
Sharing & & & & \\
Restructure the story & & & & & \\
\hline
\end{tabular}


experts for the internal validity of the model. Third, a field evaluation was employed for the external validity of the model and for reviewing its educational effectiveness. Finally, this study proposes a modified and improved final NE-Maker instructional model after reflecting upon the validity results. The research procedure is shown in Fig. 1 .

\subsection{Validity method of the NE-maker instructional model}

To secure the validity of the NE-Maker instructional model, this study went through the internal and external validity processes proposed in Richey and Klein (2007). The internal model validation is a research method for proving the efficacy of the components of a model, focusing on the model's completeness and usability. This study conducts a validity review, completed by experts, and a usability evaluation, completed by teachers. The external model validation is a research method used to confirm the model by reporting the model-use effects. This study conducts a field test to investigate the learner's responses after designing and applying the NE-Maker model-based class.

\subsubsection{Internal model validation}

To conduct the expert's review, it was important to select suitable experts for this study (Rubio et al., 2003). Thus, the selection criteria of experts were determined in line with those used in previous studies (i.e., experts had to be experienced in the education field for more than five years, held a master's and/or Ph.D. degrees in related subjects, and had a record of paper presentations and publications in related subjects). Eight experts who satisfied more than two out of three criteria were selected (Grant \& Davis, 1997; Kim, 2018; Kim, 2016; Rha \& Chung, 2001). The model validation test tool used in previous studies (Kim, 2018; Kim, 2016; Lee, 2020; Rha \& Chung, 2001) was modified according to the purpose of this study and completed after revising and improving the modified version through the pilot test by six experts. The questions consisted of 5 multiple choice questions with the 4-point Likert scale and two free narrative questions, in which overall modifications for the model and other feedback can be described. Table 6 presents the composition of experts who participated in the validation review.

To verify the model's usability, efficiency, effectiveness in real classes (Richey \& Klein, 2007), the usability evaluation was conducted with current elementary school teachers. The participants included eleven elementary school teachers who had

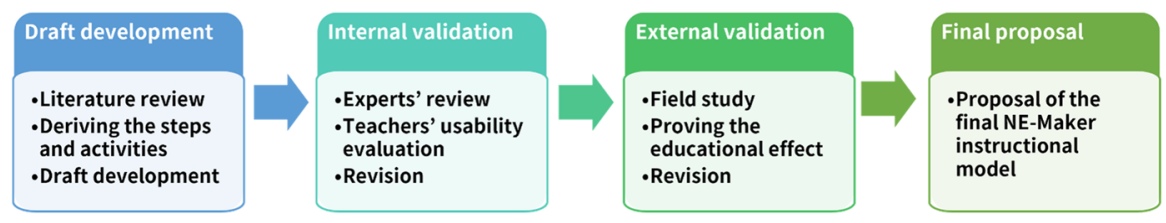

Fig. 1 The Research Procedure of NE-Maker Instructional Model Development 


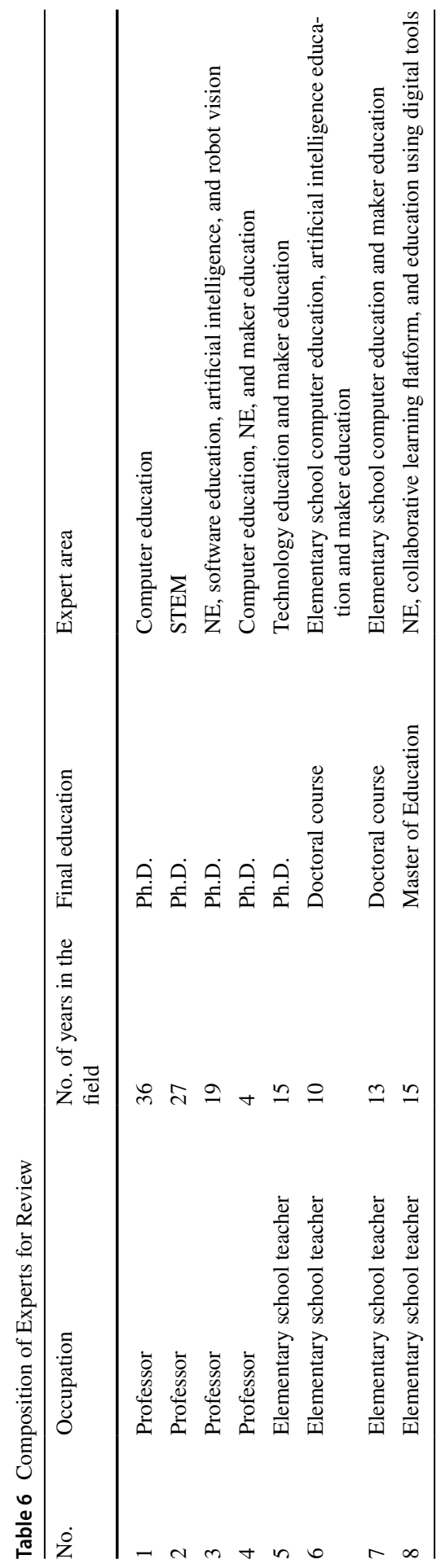


relevant education experience. The existing model usability test tool (Kim, 2018; Kim, 2016) was modified according to this study's purpose and completed through the pilot test. The final survey on the usability evaluation consisted of 6 multiple choice questions and two free narrative questions. Table 7 presents the composition of teachers who participated in the usability test.

The multiple-choice questions regarding internal model validation had content validity ratios (CVR) produced and compared according to the results measured by the Likert scale. The threshold value in the CVR varies depending on the number of panelists (Lawshe, 1975) and the content is viewed as valid when the CVR of each question is more than the threshold value. The responses to the free narrative questions were summarized and important and recurring content was used to derive the modified version of the NE-Maker instructional model.

\subsubsection{External model validation}

The field test for the external model validation aims to check whether the model has educational effectiveness when incorporated in a class. It also predicts the implications on model revision by analyzing the responses of the learners. Since the field evaluation was a study method, which was basically characterized with qualitative research (Richey \& Klein, 2007), the sampling selection was chosen, according to the study's purpose, using purposive sampling, which is one of the non-probabilistic sampling techniques. The sampling criteria were set as follows: first, schools had to do face-to-face classes despite COVID-19 as necessary for maker education; second, elementary schools had to be small and in rural areas with a student number below 60, third, schools had to be able to assign 18 instructional hours to apply the class program, and fourth, 6th-grade classes had to include software education content as part of the national curriculum. Accordingly, 13 students in total (seven male and six female) from one class of 6th-graders in J Elementary School located in a fishing village, which had a total of 54 students, participated in this study. This study was a tightly designed experimental study using a matched-pairs design, a successful study could be conducted with only a small sample size such as 10 to 20 (Roscoe, 1975).

Note that this study includes 15 students (eight males and seven females) in a 6th-grade class in C Elementary School in a rural area, a similar environment, for the purpose of conducting a comparative study to statistically strengthen the results. However, this study had the limitation in that it could not compare more than two classes in the same school because there was only one class in that grade. Table 8 presents the composition of participants in the experimental control groups for the field study.

Table 9 describes the design of the experiment in quantitative research to measure educational effectiveness. The homogeneity of both groups was verified through the maker mindset pretest before conducting the experiment. For the experimental group, that meant a class designed according to the procedure of the NE-maker instructional model, and for the control group, it meant a normal software education class that followed the textbook. A maker mindset posttest, which was the same as the pretest, was conducted after the experiment to verify the difference in the educational effectiveness between the two groups. In addition, a class satisfaction test was 


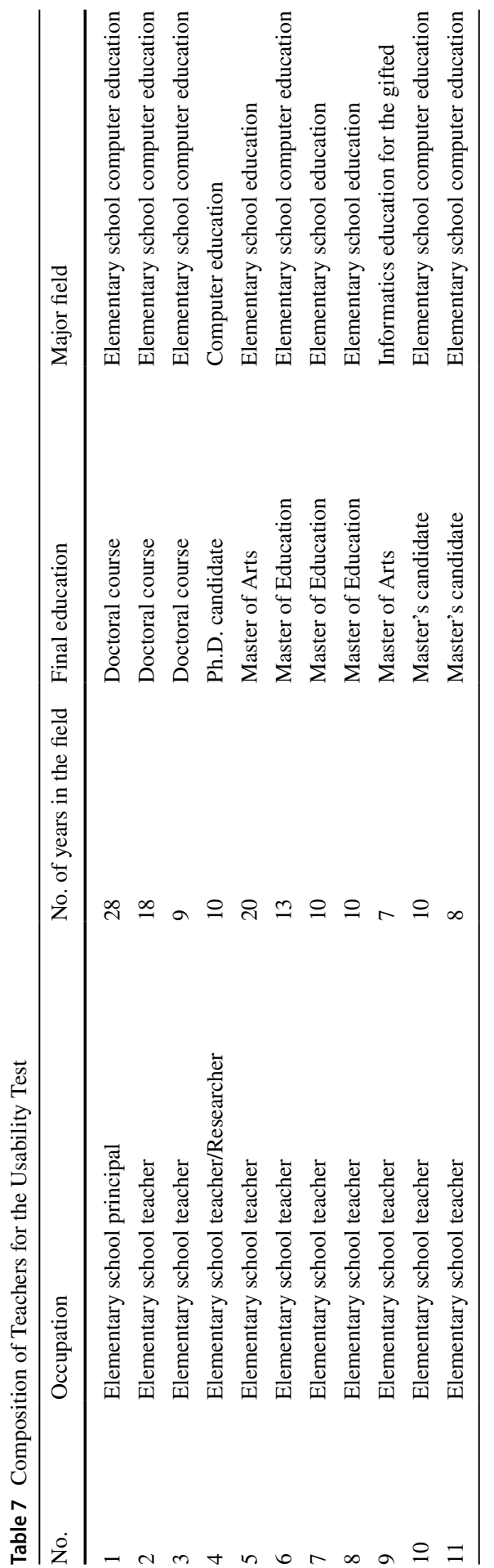


Table 8 Composition of Participants for the Field Study

\begin{tabular}{llllll}
\hline Group & Grade & No. of classes & Male & Female & Total \\
\hline Experimental group & 6 & 1 & 7 & 6 & 13 \\
Control group & 6 & 1 & 8 & 7 & 15 \\
\hline
\end{tabular}

Table 9 Design of the Experiment

\begin{tabular}{lccr}
\hline$G_{1}$ & $O_{1}$ & $X_{1}$ & $O_{3}$ \\
$G_{2}$ & $O_{2}$ & $X_{2}$ & $O_{4}$ \\
\hline$G_{1}:$ Experimental Group & \\
$G_{2}:$ Control Group \\
$O_{1}, O_{2}:$ Pretest (maker mindset test) \\
$O_{3}, O_{4}:$ Posttest (maker mindset test) \\
$X_{1}:$ Class activities according to the NE-Maker instructional model \\
$X_{2}:$ Normal software education class according to the textbook
\end{tabular}

conducted for the experimental group to assess the students' satisfaction with the class according to the NE-maker instructional model.

To verify the educational effect quantitatively, the same maker mindset test developed in Kim et al. (2020) was conducted before and after the class. The survey results were analyzed with a significance level of 0.05 using IBM SPSS Statistics 21 and a paired $t$-test was conducted to determine the change before and after the test. The composition of questions in the maker mindset test tool used in this study is presented in Table 10 (Kim et al., 2020).

The class satisfaction level was evaluated using five questions after the test and measured using the 5-point Likert scale to verify the learner's satisfaction. The questions (Lee, 2020) for the evaluation of class satisfaction were modified according to this study's purpose.

In addition, qualitative study data were collected to derive improvement for the model. More specifically, student activity sheets, photos, and e-portfolios were collected in addition to 61 student reflective journals after the completion of every session.

In addition, a short interview was conducted with the study participants. The questions used in the interview were modifications of the questions used in Lee (2020) according to this study's purpose. The first interview was conducted for 15 minutes with eight students at the break time of Session 2, which represented the first half of the field study. A second interview was then performed with 11 students for 20 minutes at the break time of Session 5, which represented the second half of the class.

In the qualitative data analysis, both the deductive approach, which was useful to verify the concept or model, and the inductive approach, which derived the category from data when prior knowledge was not sufficient, were employed (Elo \& Kyngäs, 2008). The prior studies were analyzed by the deductive approach to set up the primary code and then divided into effectiveness, advantage, and improvement to assess the data. In addition, the inductive approach was used to assign the condensed 


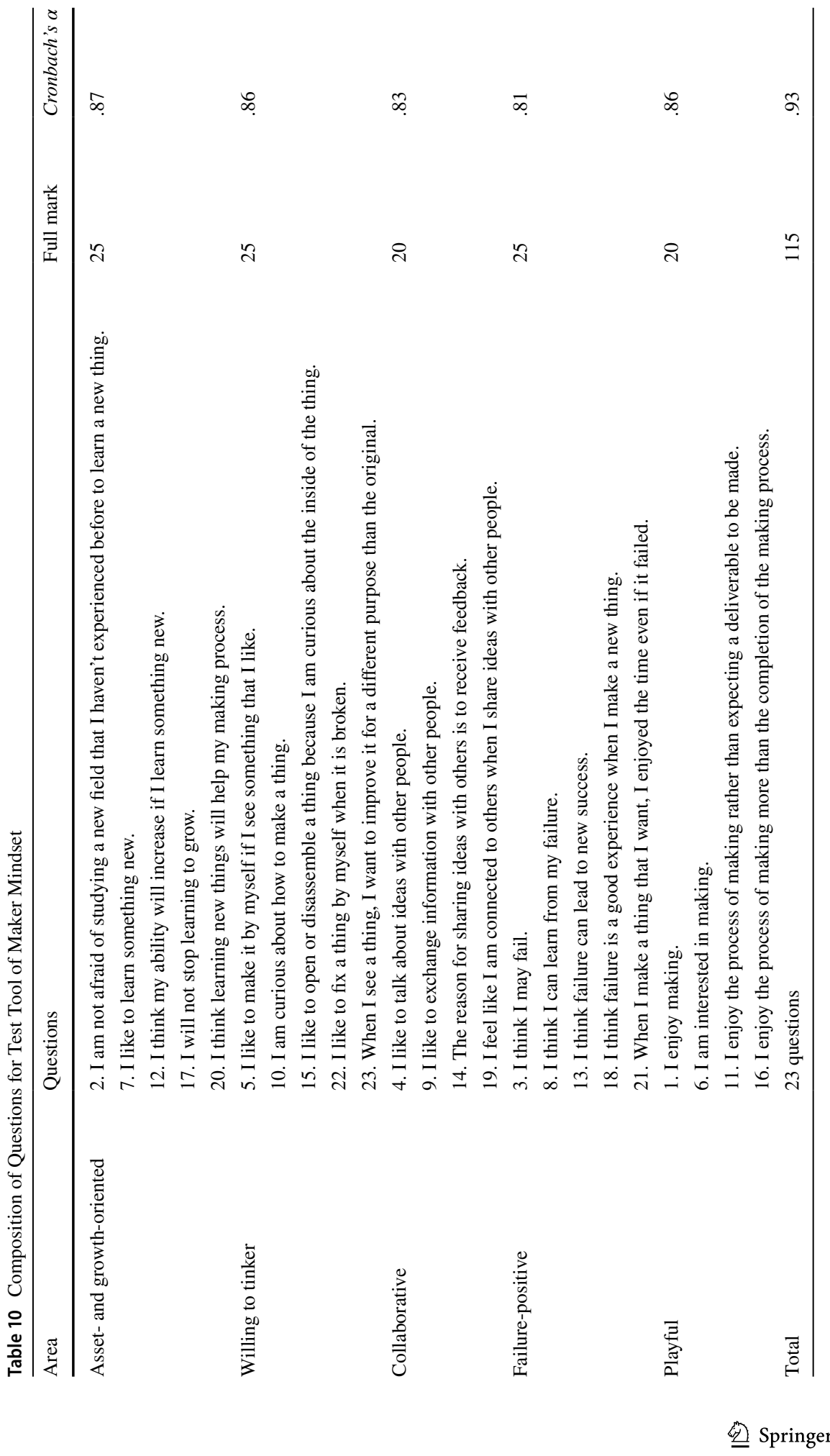


meaning unit to texts while reading the data repeatedly and classifying the texts to derive new code. The qualitative data were independently coded by researchers to ensure their reliability, and peer review studies on the results were conducted continuously to corroborate the final results. The inter-rater reliability of the qualitative data showed a substantial consistency as $\kappa=-.627$ and $p<.001$ (Landis \& Koch, 1977).

\section{Results}

\subsection{Draft development of the NE-maker instructional model through literature review}

\subsubsection{Definition of NE-maker}

The relationship of each paradigm is summarized as follows: first, there was a common point shared by both NE and design thinking, namely, that learners play the role of having agency to solves other people's problems rather than solving their own. Thus, deep empathy about the circumstances faced by others was needed, and deliverables were proposed to deepen that empathy among the learners by observing and interviewing the object before solving the problem (Carroll et al., 2010; Drew, 2019; Institute of Design at Stanford, n.d.; Riverdale \& IDEO, 2014; Hasso-Plattner-Institut, n.d.; The Interaction Design Foundation, n.d.; Yoon, 2018). In addition, even in the test step of design thinking, feedback, modification, and improvements about deliverables produced by subjects are checked. Thus, the entire process of design thinking is conducted from a user-oriented viewpoint (Carroll et al., 2010; Riverdale \& IDEO, 2014; Hasso-Plattner-Institut, n.d.; Yoon, 2018). NE is also conducted from the user-oriented perspective because it steadily considers the limitation and conditions in a literary work by making a character in a literary work into a client (Choi, 2019; Milto et al., 2020; Novel Engineering, n.d.; Portsmore \& Milto, 2018).

On the other hand, with regard to maker education, although the demands of others may be analyzed and activities to empathize with others may be practiced, depending on the ongoing project, neither were mandatory. Thus, maker education that combines design thinking and NE can expand the range of experience of learners from a maker into a learner with agency; learners thus have the opportunity to structure various types of knowledge proactively and enthusiastically (Yoon, 2018).

The difference between NE and design thinking lies in the problem's nature to be solved. Design thinking is a step-by-step method of design projects that are performed in the real world. Thus, it goes through the process to capture a problem situation that exists in the real world and solve that problem (IDEO Design Thinking, n.d.; Roffey et al., 2016; The Interaction Design Foundation, n.d.). On the other hand, NE brings the engineering design process, which is a step to solve a problem, to the field of education through convergence with literature. Thus, NE solves a virtual problem situation in literary works rather than a real-world problem situation (Milto et al., 2020; Montgomery \& Madden, 2019). 
Design thinking-based education, which is an experience that occurred during real activities related to the real world, is more meaningful from the viewpoint of experientialism and constructivism (Yoon, 2018). This is because problems related to real-life provide rich contexts and offer proactive semantic analysis, selection, decision-making, and understanding activities as conducted based on prior knowledge and prior experience of individuals in the problem-solving process. In addition, the interaction with others in that process can be a meaningful experience and provides proactive learning experiences that lead to knowledge acquisition through meaningful semantic configuration (Ackermann, 2001; Yoon, 2018).

However, unstructured problem solving is a very difficult task for students in a classroom environment, and it may hinder the exhibition of students' imagination (Lawson, 2005; McCormick \& Hynes, 2012). Furthermore, since it is not easy for students to be familiar with the step of design thinking and proactively conduct a project, students are likely to converge to established procedures and answers (Dym et al., 2005; McCormick \& Hynes, 2012). This study aims to conceptualize and propose the NE-Maker that fused design thinking and maker education based on the following strengths for elementary school students and learners: NE can practice design thinking using rich contexts in literary works for elementary school students, for whom engineering making is otherwise somewhat difficult (Milto et al., 2020), making is expanded to the social dimension beyond just the individual dimension (Yoon, 2018), and fusion activities of engineering and literature are made possible (McCormick, 2015; Milto et al., 2016).

In summary, NE-Maker refers to a project-based education method where the problem starts from empathizing with characters in a book by a learner as one with agency, and the problem is solved considering the sociocultural context based on sharing and collaboration to produce visible deliverables. In conclusion, NE-Maker is a mutually complementary form of NE, design thinking, and maker education, based on constructivism and experientialism as its pedagogical basis. These three paradigms are inter-affected as discussed above. Fig. 2 shows the relationship between NE, maker education, and design thinking.

\subsubsection{Derivation of elements of NE-maker instructional model}

The literature in relation to novel engineering, maker education, and design thinking was analyzed to derive the steps and activities in the NE-Maker instructional model for a sustainable maker education among elementary school students in rural areas. For the literature search, ERIC, Taylor \& Francis SSH, Wiley Online Library SSH, and Google Scholar were used. "Novel engineering," "engineering," and "literacy" were used as keywords to search the data in relation to NE. To collect the data in relation to maker education, key terms such as "makerspace and education," "learning," "class," "school," and "student" were combined, and key phrases such as "maker movement," "tinkering," and "maker mindset" were also used. As the keywords to searching the data in relation to design thinking, "design thinking" was used. Meanwhile, "Papert," "Piaget," "Dewey," "constructivism," "constructionism," and "experientialism" were used as search keywords for education trend research. Research papers about class models, education programs, and class design, 
Fig. 2 Relationship of Novel Engineering, Maker Education, and Design Thinking

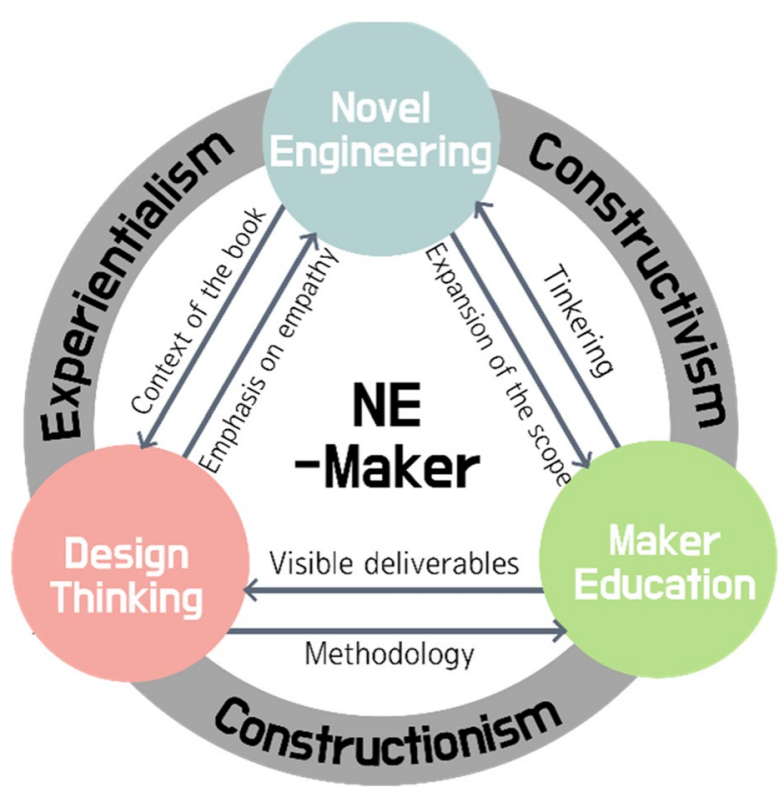

etc., which were related to education fields, came out of the search results when using the keywords listed. The number of final research papers used in the analysis was 97 papers (49 papers in maker education, 34 papers in NE, and 14 papers in design thinking).

By analyzing and summarizing the collected research papers, this study aims to identify the concepts and characteristics of maker education and reflect on the outcome for the class model. In addition, this study analyzed and categorized the steps of design thinking and matched them with the derived detailed activity elements of NE to design the steps of the class model and relevant, detailed activities. The derived elements of the NE-Maker instructional models are: explore, empathize, ideate, make, test, and share. Table 11 summarizes the literature review results to derive these elements.

\subsubsection{Draft development of the NE-maker instructional model}

Based on the analysis of results of previous studies, a draft for the NE-Maker instructional model was developed, as shown in Fig. 3. Among the steps, "explore and empathize" and "make and test" are combined because they are frequently repeated. The combined steps were devised to occur frequently whenever each step was completed. Each step can be organically moved or used iteratively as circumstances demand. Also, all activities of the NE-Maker instructional model should be group projects. NE-Maker is an activity inside the classroom that solves problems contained in a book as a model for practice, but it can lead to real-world solutions if students improve the maker mindset based on practice inside the classroom.

The activities included in each step are as follows: 
Table 11 Literature Review for NE-Maker Instructional Model Elements

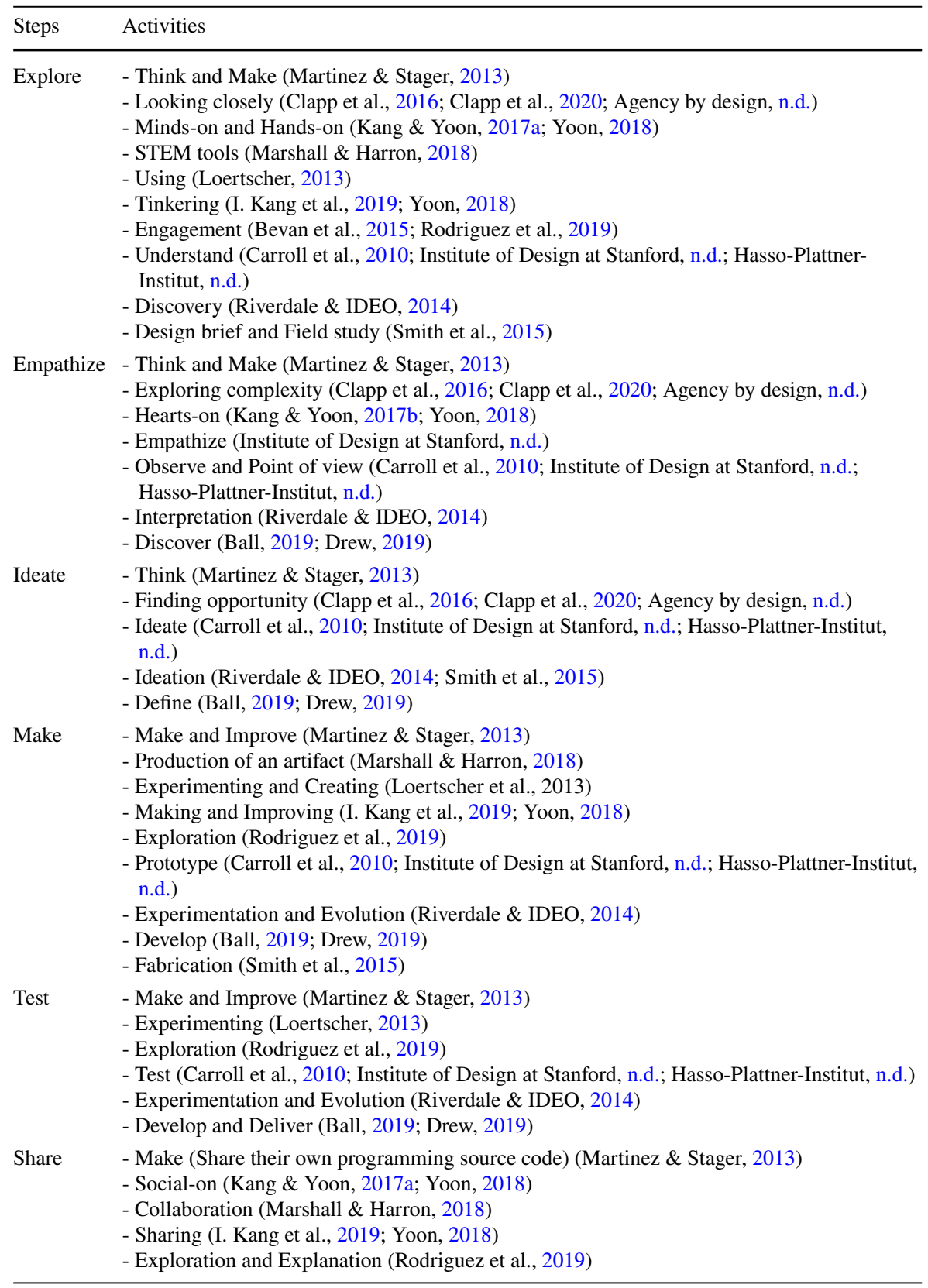

- Explore \& Empathize: understanding materials (Choi, 2019; Loertscher, 2013; Martinez \& Stager, 2013; Rodriguez et al., 2019), reading a book (Choi, 2019; Hong \& Cho, 2019; Novel Engineering, n.d.), identifying the problem (Carroll 


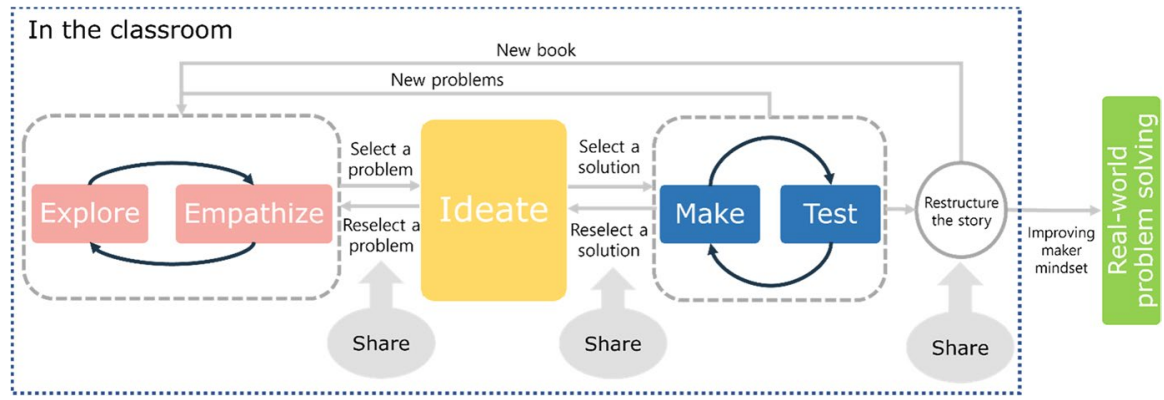

Fig. 3 Draft of the NE-Maker Instructional Model

et al., 2010; Choi, 2019; Cohen et al., 2017; Drew, 2019; Hong \& Cho, 2019; Institute of Design at Stanford, n.d.; Kapur, 2016; Kim \& Lee, 2020; Milto et al., 2020; Novel Engineering, n.d.; Portsmore \& Milto, 2018), and reviewing the problem (Carroll et al., 2010; Choi, 2019; EiE, 2020; Teach Engineering, n.d.; Kim et al., 2020; Milto et al., 2020; Novel Engineering, n.d.; Portsmore, 2010; Portsmore \& Milto, 2018; Riverdale \& IDEO, 2014; Rodriguez et al., 2019; Smith et al., 2015)

- Ideate: ideating (Carroll et al., 2010; Choi, 2019; EiE, 2020; Teach Engineering, n.d.; Institute of Design at Stanford, n.d.; Martinez \& Stager, 2013; Novel Engineering, n.d.; Palinscar \& Duke, 2004; Portsmore, 2010; Smith et al., 2015), choice (Portsmore, 2010; Riverdale \& IDEO, 2014), and designing (Choi, 2019; Hong \& Cho, 2019; Kim \& Lee, 2020; Martinez \& Stager, 2013; Milto et al., 2020; Novel Engineering, n.d.; Portsmore \& Milto, 2018)

- Make \& Test: prototyping \& test (Carroll et al., 2010; Drew, 2019; EiE, 2020; Teach Engineering, n.d.; Institute of Design at Stanford, n.d.; Portsmore, 2010; Riverdale \& IDEO, 2014; Rodriguez et al., 2019; Smith et al., 2015; The Interaction Design Foundation, n.d.), learning (Portsmore \& Milto, 2018), making the familiar unfamiliar (Portsmore \& Milto, 2018), and improvement (Choi, 2019; EiE, 2020; Teach Engineering, n.d.; Hong \& Cho, 2019; Kim \& Lee, 2020; Milto et al., 2020; Portsmore, 2010; Portsmore \& Milto, 2018; Yoon, 2018)

\subsection{Result of internal model validation}

The results of the validity evaluations conducted with eight experts are presented in Table 12. The threshold of the CVR was .75 or higher to verify the validity when eight panelists participated in a panel (Lawshe, 1975), and all areas satisfied the threshold. Thus, the validity of the developed NE-Maker instructional model was confirmed.

The results of the usability reviews of the model by eleven panelists, current elementary school teachers, are presented in Table 13. The minimum threshold of the CVR when the eleven panelists participated in the panel was .59 (Lawshe, 1975), and all questionnaires were satisfied. Thus, the validity of the NE-Maker instructional model was verified in terms of usability. However, the averages in the detailed 


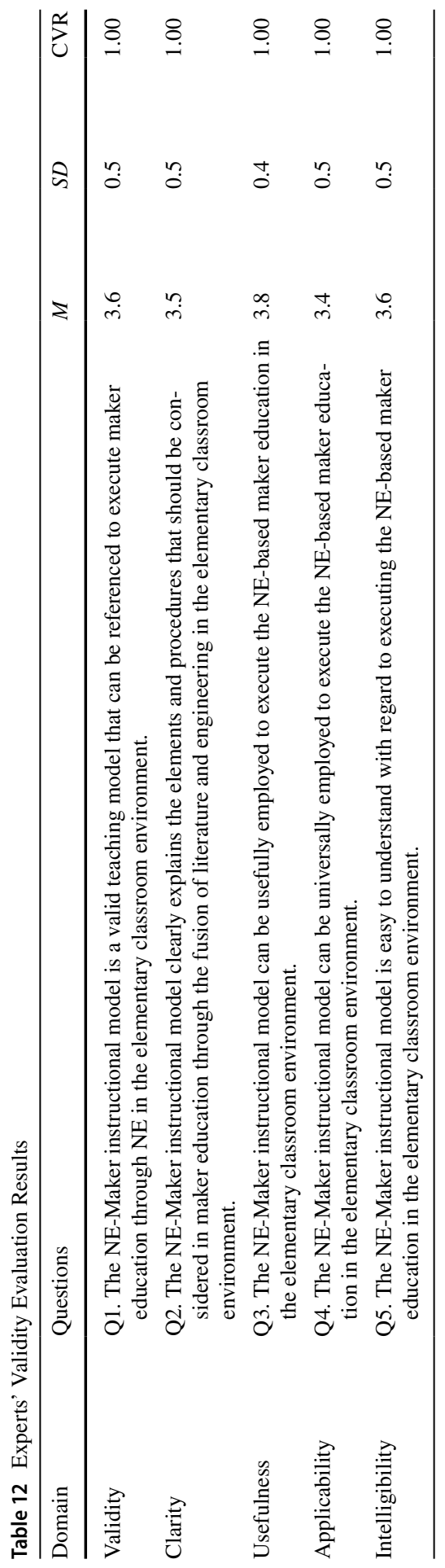




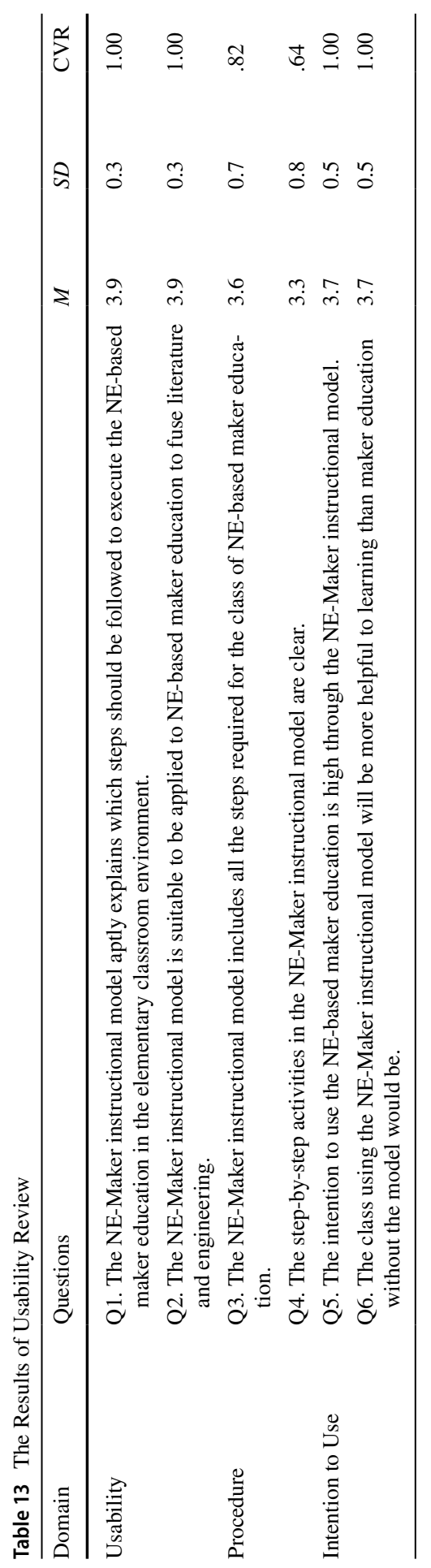


procedure sections were relatively lower than those in other sections, which required modification. Accordingly, the model was updated by considering common feedback in the free narrative-type questions.

To assess possible improvements of the NE-Maker instructional model, opinions collected from the free narrative-type questions in the internal validity process were analyzed. The suggested improvements ascertained from common opinions are presented in Table 14

The modified NE-Maker instructional model based on the improvements is shown in Fig 4.

The activities included in each step are as follows:

- Tinker: Exploration of, and development of familiarity with, relevant tools and materials

- Explore and Empathize: Review the background knowledge of students, read a book, recall students experiences, interview empathy, and discover the problem

- Find a solution: Coming up with the solution, selecting the solution, refining the solution, and designing the solution

- Create and Test: Planning, self-learning, repeating production and testing, making the familiar unfamiliar, and modifying the deliverable

- Share \& Improve: Sharing the deliverable, exchanging feedback, and improving the deliverable

- Rewrite the story: Rewrite with imagination, share the story and deliverables, and reverse thinking.

The reflective journal writing activity is performed in every step

Table 14 Experts' Opinions and Improvements

\begin{tabular}{|c|c|}
\hline Opinions & Improvement \\
\hline $\begin{array}{l}\text { - The advantages of NE require emphasis to be } \\
\text { differentiated from existing maker education } \\
\text { models. } \\
\text { - Since "re-structure the story" is an important } \\
\text { activity, it should be emphasized more proac- } \\
\text { tively. } \\
\text { - Writing is a very important activity in NE. }\end{array}$ & $\begin{array}{l}\text { - "Rewrite the story" should be arranged as a sepa- } \\
\text { rate step and emphasized. }\end{array}$ \\
\hline $\begin{array}{l}\text { - It would be better to add journal writing to all } \\
\text { processes. }\end{array}$ & $\begin{array}{l}\text { - The opportunity for reflection should be expanded } \\
\text { through journal writing every hour. }\end{array}$ \\
\hline $\begin{array}{l}\text { The collaboration and improvements, which } \\
\text { occurred in the idea concept and production } \\
\text { process should be emphasized in a cyclic con- } \\
\text { structure. }\end{array}$ & $\begin{array}{l}\text { - Performing activities are represented by cyclical } \\
\text { and repeated forms. }\end{array}$ \\
\hline $\begin{array}{l}\text { - This is a class that is possible after having engi- } \\
\text { neering competency. } \\
\text { - The willingness to participate can be actively } \\
\text { solicited through tinkering. } \\
\text { - It would be better to add activities that students } \\
\text { perform and enjoy as a maker. }\end{array}$ & $\begin{array}{l}\text { - By adding a tinker step, the level of understanding } \\
\text { materials and tools can be elevated and the learn- } \\
\text { ing motivation of making can be induced. }\end{array}$ \\
\hline
\end{tabular}




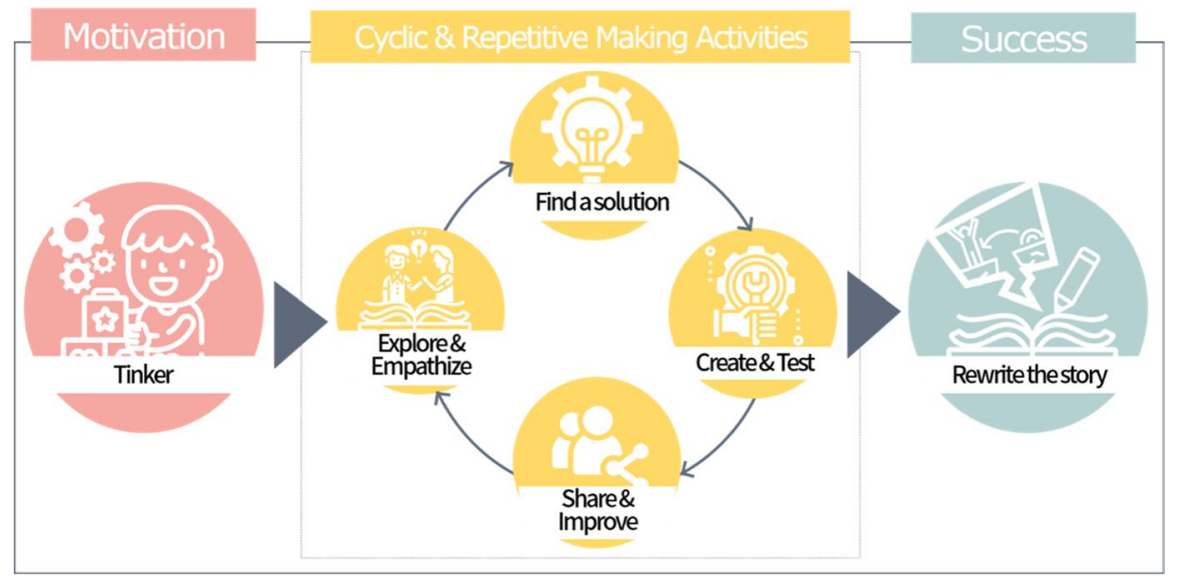

Fig. 4 Revised NE-Maker Instructional Model

\subsection{Result of external model validation}

\subsubsection{Result of field test}

To apply the NE-Maker instructional model, the books for the class were selected based on the selection criteria of books (Kim, 2020a). They consisted of Hello Lighthouse by Sophie Blackall and Anatole and the Cat by Eve Titus. The literary merit of both books was recognized as both won the Caldecott award. Both books matched with the selection criteria for books (Kim, 2020b) because students could empathize with the narrative content and the books also presented engineering problems to be solved. The covers of the books used in the class are shown in Fig. 5.

COBL-S, which was made by COBL, was employed for teaching aids of making to be used in the class. COBL-S is an Arduino Leonardo-based device by which artifacts can be made through assembly of various blocks with sensors and actuators, a form of LEGO's Duplo blocks. COBL-S consists of a COBL board, which is a mainboard, a temperature sensor, light sensor, infrared (IR) sensor, ultrasonic sensor, button switch, and joystick, which act as input devices. Two direct current motors, three external light-emitting diodes (LED) servo motors, a 4-digit 7 segment LED display, a universal serial bus (USB) port, and a USB handheld fan act as output devices, and various blocks and consumables serve as decorations for the deliverables. In this study, various decoration materials and recycled products were incorporated in making. The advantage of COBL-S is that students can connect needed parts intuitively using specially manufactured Arduino shields, which is in contrast with other board-based teaching aids that are difficult for elementary school students to use because students require some understanding of pins for making. In addition, it has the advantage of supporting a wireless connection via Bluetooth along with a wired connection when connecting a computer and teaching aids, which can produce moving making products. The configuration of COBL-S is shown in Fig. 6 (COBL, n.d.). 


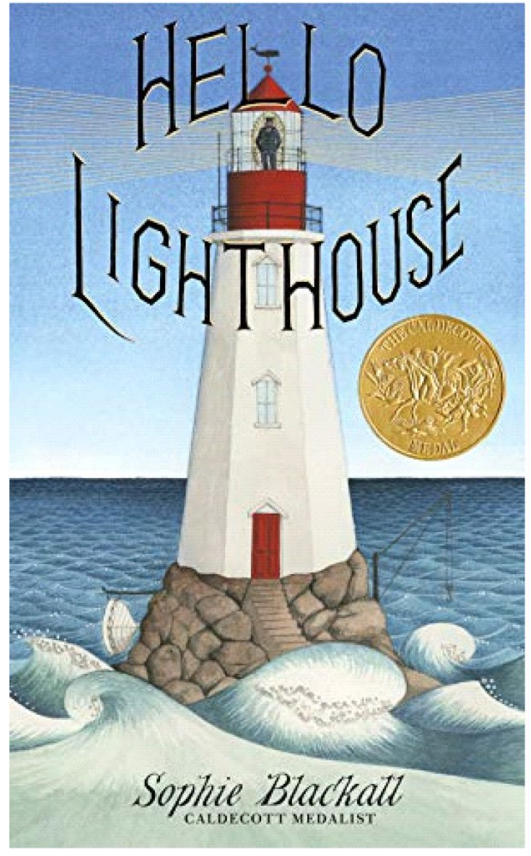

(a) Hello Lighthouse

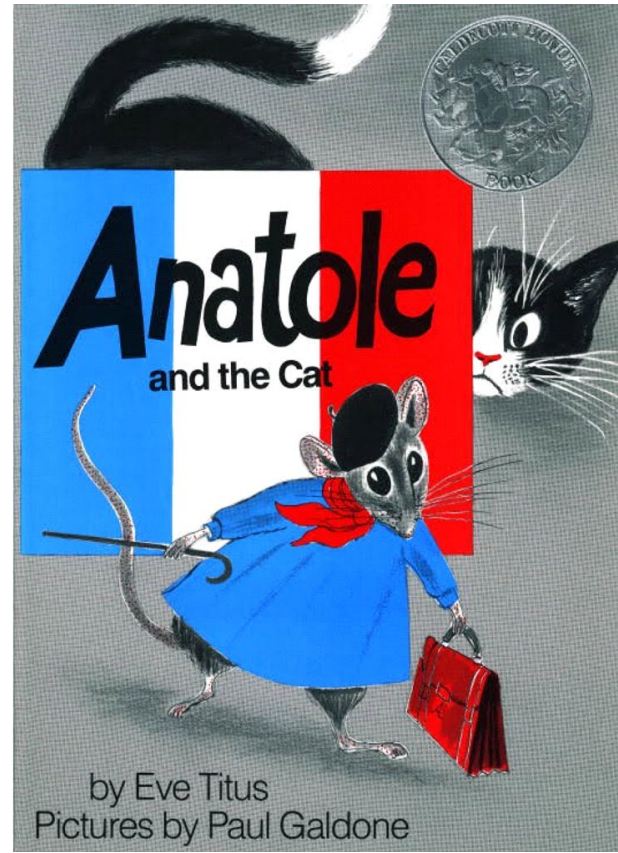

(b) Anatole and the Cat

Fig. 5 The Covers of the Books Used in the Class

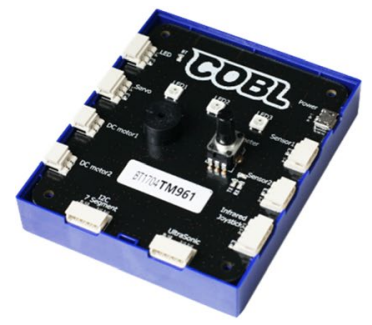

(a) $C O B L$ board

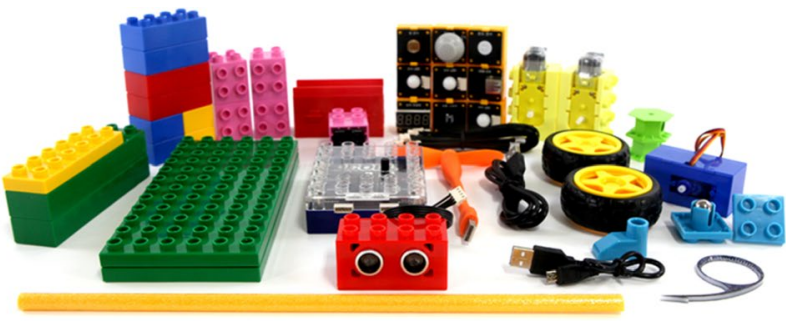

(b) Components of COBL-S

Fig. 6 Configuration of COBL-S

The supported programming language was developed based on Scratch and app inventor, which are educational programming languages. This is a program that is installed on a computer. Thus, Internet connection is not required and the program can be used in school environments of rural regions where the infrastructure is lacking. Because it can support a block-typed programming language suitable for the difficulties of teaching aids, it can be used by various age groups from kindergarten to middle school. Because of this, COBL-S was found suitable to be used for elementary school students in rural regions, who are beginners of making in this 
study. In addition, Internet of things (IoT)-based making works can also be produced by providing our own IoT server. The programming screen of COBL Scratch that is used to produce making works using COBL-S in the field test is shown in Fig. 7 (COBL, n.d.).

The field test was conducted for three weeks from September 14-28, 2020. To fully secure the practice and production times, which were key activities of the maker education, one session was taken for three to four hours, and the total hours of the class spanned 18 hours. The project activities were conducted by groups of three to four persons. Lesson plans for the field test is presented in Table 15. Fig. 8 shows the class activity photos according to the NE-Maker instructional model.

\subsubsection{Educational effectiveness}

The maker mindset pretest was conducted before the experiment to identify the homogeneity of experimental and control groups and an independent two-sample t-test was subsequently conducted. Levene's test was performed to check whether the assumption of the equality of variance was met. The test result shows that the total maker mindset had $F=0.13$ and $p=.724$, which satisfied the assumption of the equality of variance. In addition, the results of the sub-sections were as follows: asset- and growth-orientation had $F=0.34, p=.567$, willingness to tinker had $F$ $=0.06, p=.804$, collaboration had $F=0.31, p=.582$, failure-positivity had $F=$ $0.10, p=.756$, and playfulness had $F=2.20, p=.15$. Thus, the null hypothesis that the assumption of the equality of variance was satisfied in all areas was adopted. Accordingly, an independent two-sample t-test was conducted.

The experimental group had $M=80.0, S D=11.2$, and the control $\operatorname{group}$ had $M$ $=81.7, S D=9.4$ for the total maker mindset. The independent two-sample t-test results show $t=0.31$ and $p=.762$ for the mean difference of the maker mindset between two groups, which verified that the two groups were homogeneous

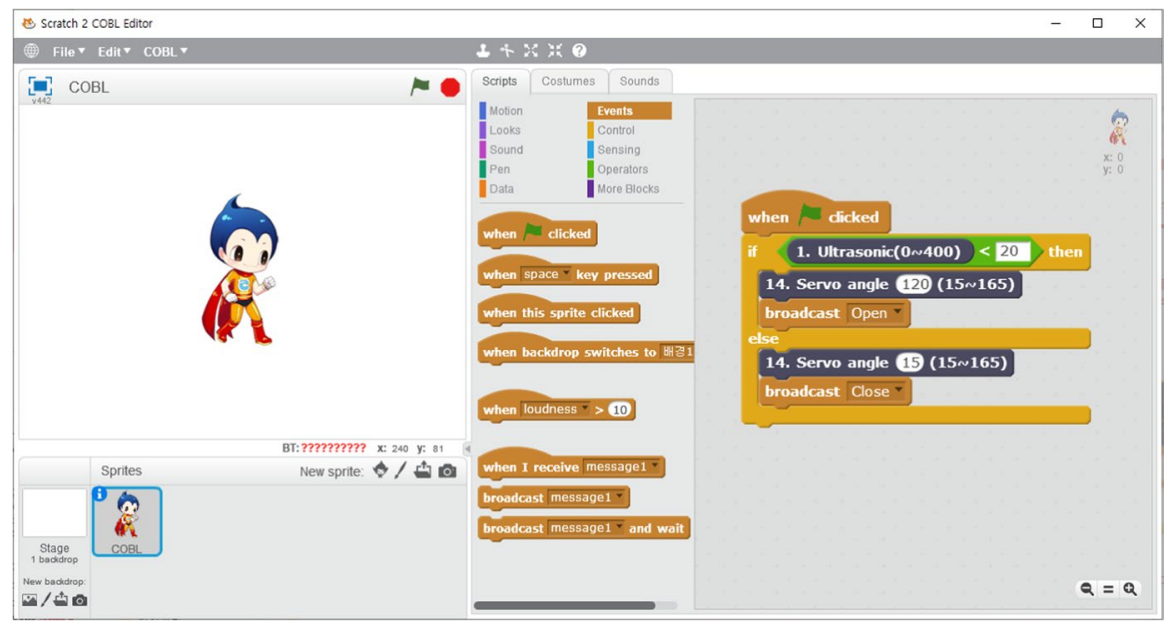

Fig. 7 COBL Scratch 


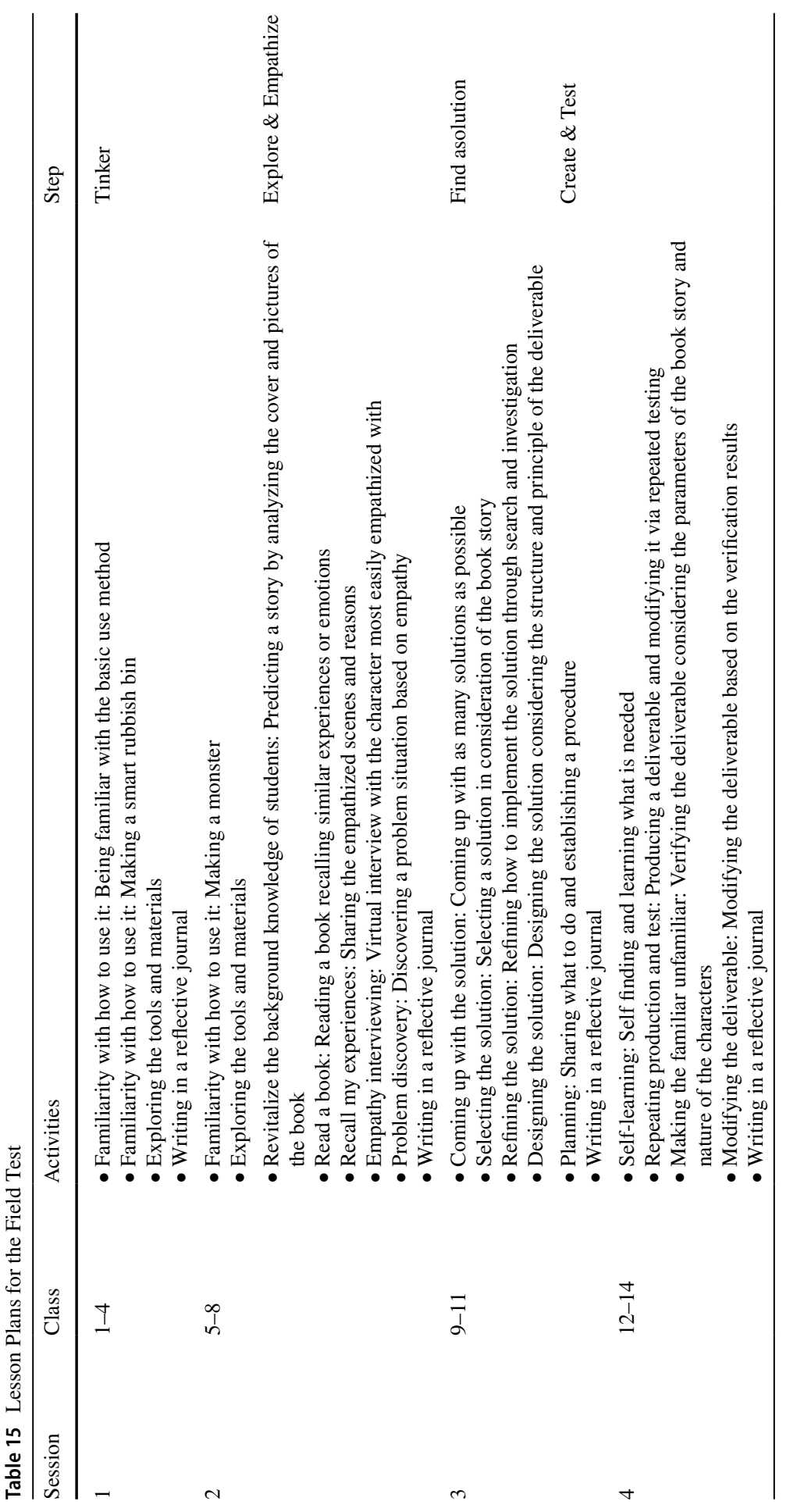




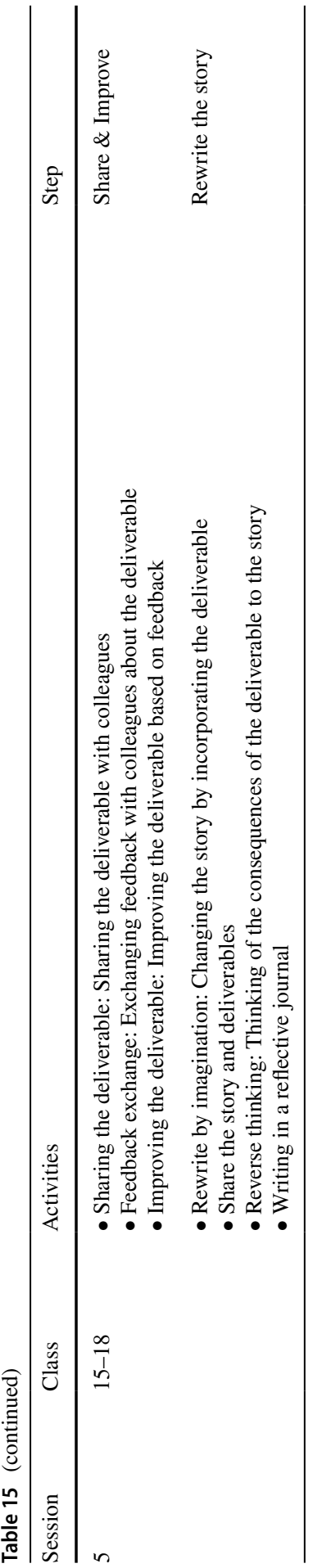

第 Springer 


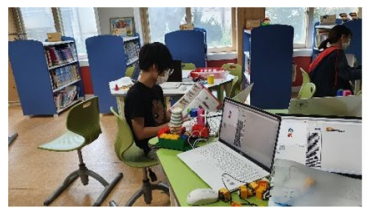

(a) Tinker

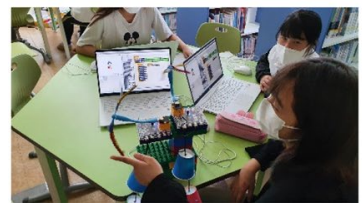

(d) Create \& Test

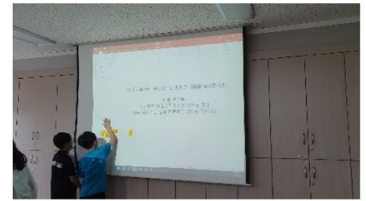

(b) Explore \& Empathize

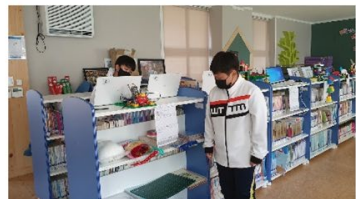

(e) Share \& Improve

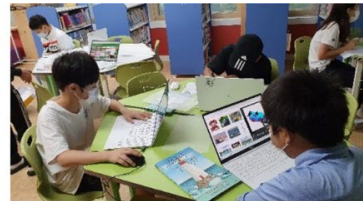

(c) Find a Solution

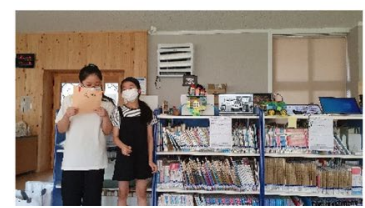

(f) Rewrite the Story

Fig. 8 Class Activities of Each Step

at a .05 significance level $(p>.05)$. The sub-sections exhibited that asset- and growth-orientation had $t=0.67, p=.507$, willingness to tinker had $t=0.62, p$ $=.539$, collaboration had $t=1.63, p=.116$, failure-positivity had $t=-1.20, p=$ .240 , and playfulness had $t=-0.30, p=.768$, which verified that the two groups were statistically homogeneous at a .05 significance level in all areas $(p>.05)$. Table 16 presents the pretest results of the maker mindset.

After the pretest, the experimental group had the maker education class according to the NE-Maker instruction model, and the control group had the software education class according to existing textbooks. Then a posttest was conducted to compare the difference between the two groups. The posttest was conducted with

Table 16 Comparison of the Pretest Results of the Maker Mindset between Experimental and Control Groups

\begin{tabular}{|c|c|c|c|c|c|c|c|c|}
\hline \multirow[t]{2}{*}{ Area } & \multirow[t]{2}{*}{ Group } & \multirow[t]{2}{*}{$n$} & \multirow[t]{2}{*}{$M$} & \multirow[t]{2}{*}{$S D$} & \multicolumn{2}{|c|}{ Levene's test } & \multirow[t]{2}{*}{$t$} & \multirow[t]{2}{*}{$p$ (2-tailed) } \\
\hline & & & & & $\boldsymbol{F}$ & $p$ & & \\
\hline \multirow[t]{2}{*}{ Asset- and growth-oriented } & Experimental & 13 & 17.2 & 2.4 & 0.34 & .567 & 0.67 & .507 \\
\hline & Control & 15 & 18.1 & 3.9 & & & & \\
\hline \multirow[t]{2}{*}{ Willing to tinker } & Experimental & 13 & 17.3 & 4.4 & 0.06 & .804 & 0.62 & .539 \\
\hline & Control & 15 & 18.3 & 4.3 & & & & \\
\hline \multirow[t]{2}{*}{ Collaborative } & Experimental & 13 & 12.5 & 2.1 & 0.31 & .582 & 1.63 & .116 \\
\hline & Control & 15 & 14.1 & 3.1 & & & & \\
\hline \multirow[t]{2}{*}{ Failure-positive } & Experimental & 13 & 18.2 & 2.7 & 0.10 & .756 & -1.20 & .240 \\
\hline & Control & 15 & 16.8 & 3.5 & & & & \\
\hline \multirow[t]{2}{*}{ Playful } & Experimental & 13 & 14.8 & 3.2 & 2.20 & .150 & -0.30 & .768 \\
\hline & Control & 15 & 14.3 & 4.3 & & & & \\
\hline \multirow[t]{2}{*}{ Total } & Experimental & 13 & 80.0 & 11.9 & 0.13 & .724 & 0.31 & .762 \\
\hline & Control & 15 & 81.7 & 9.4 & & & & \\
\hline
\end{tabular}


the same questionnaire of the pretest and the means obtained in the test between two groups were compared.

Levene's test was performed for the test of equality of variance, which was then verified as $F=0.07, p=.800$ of the total maker mindset. The results of the sub-sections were as follows: asset- and growth-orientation had $F=2.55, p=.122$, willingness to tinker had $F=0.04, p=.848$, collaboration had $F=0.00, p=.997$, failurepositivity had $F=4.08, p=.054$, and playfulness had $F=0.11, p=.741$. Thus, the assumption of the equality of variance was satisfied in all areas so that an independent two-sample t-test could be conducted.

The experimental group had $M=92.6, S D=9.4$, and the control group had $M=84.9, S D=9.5$ for the total maker mindset, which indicated that the mean of the experimental group was higher. In addition, the results of the independent two-sample t-test were $t=-2.16, p=.040$, which verified that the mean difference between the two groups was statistically significant at a .05 significance level $(p<.05)$. Conclusively, the above results verified that the maker education class with the NEMaker instructional model had a positive impact on the maker mindset more than the software education class with the existing textbook did.

The results of the sub-sections demonstrated that the means of the experimental group were higher than those of the control group in all areas. The results of students being asset- and growth-oriented in the experimental group were $M=20.4$, $S D=1.9$, and those of the control group were $M=17.9, S D=2.8$, which verified that the mean of the experimental group was higher. The results of mean difference were $t=-2.72, p=.011$, which were also statistically significant at a .05 significance level $(p<.05)$. The results of students being failure-positive in the experimental group had $M=21.5, S D=1.9$, and the control group had $M=18.7, S D=3.7$, which showed that the mean of the experimental group was higher. The independent-sample t-test results were $t=-2.48, p=.020$, which verified that the difference was statistically significant. Asset- and growth-oriented characteristics were a competence related to the development of learners' problem-solving ability that takes challenging tasks and promotes a steady growth. In addition, the failure-positive characteristic is a competence that describes the ability to learn new things in the activity process even if the deliverable production fails. Ultimately, it means that the NE-Maker class has a more positive impact on students who faced challenging tasks and meant steady growth since students interpreted failures more positively as a motivation to grow than did students in the existing software education class.

The results of students being willing to tinker in the experimental group were $M=19.7, S D=4.2$, and those of the control group were $M=19.1, S D=3.9$, which indicated that the mean of the experimental group was higher, but this difference was not statistically significant as $t=0.37, p=.717(p>.05)$. The results of students being collaborative in the experimental group were $M=14.7, S D=3.0$, and those of the control group were $M=13.1, S D=3.0$, but this difference was also not statistically significant as $t=-1.42, p=.168(p>.05)$. Finally, students being playful in the experimental group were $M=16.4, S D=2.4$, and those of the control group were $M=16.1, S D=2.5$, which indicated that the mean of the experimental group was higher, but this difference likewise was not statistically significant as $t=-0.27$, $p=.787(p>.05)$. 
Being willing to tinker is the competence to discover a problem based on ceaseless curiosity and implement creative ideas using various tools and materials, and being collaborative is the competence to pursue collaboration through sharing making activity processes and exchange of various kinds of knowledge with people. Moreover, being playful refers to competence to enjoy making itself and to proactively participate. The reason for not having a significant difference between the NE-Maker and software education classes in those areas was because the software education class also pursued the activities related to those competencies. Table 17 summarizes the posttest results of the maker mindset.

To verify the educational effectiveness of the NE-Maker instructional model, the maker mindset test (Kim \& Lee, 2020) was conducted before and after the class and a paired t-test was conducted to compare the results. The comparison results of the pre- and post-maker mindset tests are presented in Table 18.

The posttest result of the maker mindset $(M=92.6, S D=9.4)$ showed improved over the pre-test $(M=80.0, S D=11.9)$. The result was statistically significant, with $t=-12.62$ and $p<.001$. The results of the subsections exhibited that asset-and growth-oriented had 17.2 of the pre-test average and 20.4 of the post-test average, with $t=-3.49$ and $p=.004(p<.05)$; willing to tinker had 17.3 of pre-test average and 19.7 of post-test average, with $t=-3.31$ and $p=.006(p<.05)$; collaborative had 12.5 of pre-test average and 14.7 of post-test average, with $t=-2.23$ and $p=.008(p<.05)$; failure-positive had 18.2 of pre-test average and 21.5 of posttest average, with $t=-3.23$ and $p=.002(p<.05)$; and playful had 14.8 of pretest average and 16.4 of post-test average, with $t=-1.62$ and $p=.005(p<.05)$. These results showed statistically significant improvements in all sections $(p<.05)$. In summary, there were statistically significant improvements in the entire maker mindset and all five of the sub-sections, which verifies the educational effectiveness of the NE-Maker instructional model.

Table 17 Comparison of the Posttest Results of the Maker Mindset between Experimental and Control Groups

\begin{tabular}{|c|c|c|c|c|c|c|c|c|}
\hline \multirow[t]{2}{*}{ Area } & \multirow[t]{2}{*}{ Group } & \multirow[t]{2}{*}{$n$} & \multirow[t]{2}{*}{$M$} & \multirow[t]{2}{*}{$S D$} & \multicolumn{2}{|c|}{ Levene's test } & \multirow[t]{2}{*}{$t$} & \multirow[t]{2}{*}{$p(2$-tailed $)$} \\
\hline & & & & & $\boldsymbol{F}$ & $p$ & & \\
\hline \multirow[t]{2}{*}{ Asset- and growth-oriented } & Experimental & 13 & 20.4 & 1.9 & 2.55 & .122 & -2.72 & .011 \\
\hline & Control & 15 & 17.9 & 2.8 & & & & \\
\hline \multirow[t]{2}{*}{ Willing to tinker } & Experimental & 13 & 19.7 & 4.2 & 0.04 & .848 & -0.37 & .717 \\
\hline & Control & 15 & 19.1 & 3.9 & & & & \\
\hline \multirow[t]{2}{*}{ Collaborative } & Experimental & 13 & 14.7 & 3.0 & 0.00 & .997 & -1.42 & .168 \\
\hline & Control & 15 & 13.1 & 3.0 & & & & \\
\hline \multirow[t]{2}{*}{ Failure-positive } & Experimental & 13 & 21.5 & 1.9 & 4.08 & .054 & -2.48 & .020 \\
\hline & Control & 15 & 18.7 & 3.7 & & & & \\
\hline \multirow[t]{2}{*}{ Playful } & Experimental & 13 & 16.4 & 2.4 & 0.11 & .741 & -0.27 & .787 \\
\hline & Control & 15 & 16.1 & 2.5 & & & & \\
\hline \multirow[t]{2}{*}{ Total } & Experimental & 13 & 92.6 & 9.4 & 0.07 & .800 & -2.16 & .040 \\
\hline & Control & 15 & 84.9 & 9.5 & & & & \\
\hline
\end{tabular}


Table 18 Comparison of Maker Mindset Test

\begin{tabular}{lllllll}
\hline Area & Test & $n$ & $M$ & $S D$ & $t$ & $p$ (2-tailed) \\
\hline Asset- and growth-oriented & Pre & 13 & 17.2 & 2.4 & -3.49 & .004 \\
& Post & 13 & 20.4 & 1.9 & & \\
Willing to tinker & Pre & 13 & 17.3 & 4.4 & -3.31 & .006 \\
& Post & 13 & 19.7 & 4.2 & & \\
Collaborative & Pre & 13 & 12.5 & 2.1 & -2.23 & .008 \\
& Post & 13 & 14.7 & 3.0 & & \\
Failure-positive & Pre & 13 & 18.2 & 2.7 & -3.23 & .002 \\
\multirow{3}{*}{ Playful } & Post & 13 & 21.5 & 1.9 & & .005 \\
& Pre & 13 & 14.8 & 3.2 & -1.62 & \\
Total & Post & 13 & 16.4 & 2.4 & & \\
& Pre & 13 & 80.0 & 11.9 & -12.62 & $<.001$ \\
& post & 13 & 92.6 & 9.4 & & \\
\hline
\end{tabular}

Moreover, to assess class satisfaction of the NE-Maker instructional model, a survey on satisfaction consisting of five questions was conducted, and the survey results showed the total satisfaction average to be 4.5 , which confirmed that the learners were considerably satisfied with the class. Table 19 presents the evaluation results of class satisfaction.

Analyzed results of the qualitative data, such as reflective journals and short interviews, revealed that the NE-Maker instructional model proved to be effective in bolstering interest in making, sharing, and growth-oriented collaboration, keys to the maker mindset. The advantages yielded by the model were the following: strengthening engineering literacy, enhancing literacy, and increasing diversity. In particular, in relation to literacy, the effects such as the enhancement of communication competence, improvement of reading-related ability, and joy of reading were significantly derived. This is meaningful in the sense that the NE-Maker instructional model improved listening, speaking, reading, and writing abilities because it is a fusion class of language arts and engineering.

Table 19 The Evaluation Results of Class Satisfaction

\begin{tabular}{|c|c|c|c|c|}
\hline Questions & $M$ & $S D$ & Min & $\operatorname{Max}$ \\
\hline Q1. I think the class was interesting and fun. & 4.5 & 0.7 & 3 & 5 \\
\hline Q2. I will continue participating in this class in the future. & 4.5 & 0.7 & 3 & 5 \\
\hline Q3. I am satisfied with the participation in this class. & 4.6 & 0.7 & 3 & 5 \\
\hline Q4. I could understand the learning content better after this class. & 4.2 & 0.7 & 3 & 5 \\
\hline Q5. I would like to recommend this class to other friends. & 4.5 & 0.8 & 3 & 5 \\
\hline Total & 4.5 & 0.7 & 3 & 5 \\
\hline
\end{tabular}




\subsection{Proposal of the final NE-maker instructional model}

Based on the results obtained through the external validation procedure, the following improvements were achieved:

- "Refining the solution" activity should be integrated and presented with the "designing the solution" activity in the "Find a solution" step: because two activities were conducted simultaneously throughout the class, they need to be presented in an integrated manner.

- The "self-learning" activity should be integrated and presented within the "repeating production and test" activity in the "Create and Test" step: it is natural to integrate and present self-learning with the production and test process without separating them because the need for self-learning is felt spontaneously in the production and test processes.

The final NE-Maker instructional model based on the improvements is shown in Fig. 9.

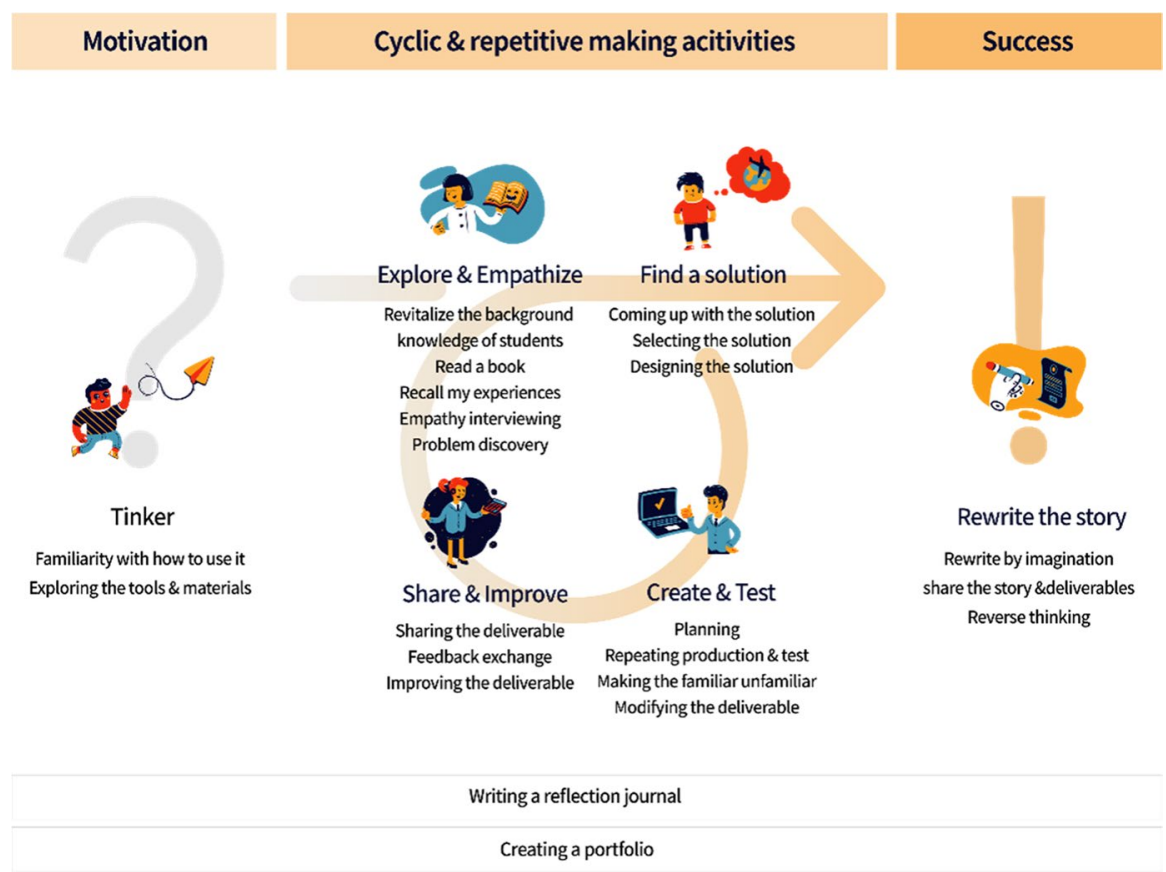

Fig. 9 Final NE-Maker Instructional Model 


\section{Discussion}

This study developed a draft for the NE-Maker instructional model after conducting a literature review and proposed a final instructional model consisting of six steps and 20 subactivities after internal and external validation and modification. This study's contributions compared to existing studies are as follows: first, this study aimed to reduce the ICT educational gap (Ainley, 2006; Chandra et al., 2021; Kim et al., 2014; Lembani et al., 2020; Liao \& Chang, 2010; Umar \& Jalil, 2012) between rural and urban elementary students by using novel engineering and maker education. Tinkering and project-based learning are conducted in the NE-Maker instructional model developed in this study using teaching tools where coding can be done. Incorporating this model into a class can be applied with low cost if recycled products and low-cost teaching tools, such as Arduino and Micro:bit, are employed as making materials (Kim et al., 2020). In this regard, the NE-Maker instructional model can be fully employed even in rural schools where educational resources are scarce, and the opportunity for classes using ICT can be extended thereby reducing the educational gap between urban and rural students.

Second, a limited class hour can be effectively used to improve ICT competence via the fusion class of literacy and engineering. Since students in rural regions have lower ICT literacy than students in urban regions (Ainley, 2006; Chandra et al., 2021; Kim et al., 2014; Lembani et al., 2020; Liao \& Chang, 2010; Umar \& Jalil, 2012), they should be more exposed to education to alleviate this difference. The NE-Maker Instructional model proposed in this study was developed for the integration of engineering with language arts and has been verified to have a positive effect on both literacy and engineering. Thus, existing class times of language arts and engineering can be used to incorporate the model which would lead to more beneficial effects. Ultimately, the model can have a very positive impact on achieving the inclusive and equitable quality education pursued by SDG 4 (UNESCO, 2017; United Nations, 2015).

Third, the NE-Maker concept has been established as a project-based education method in which a learner has agency (engineering designer), and empathizes with the character (customer) in a book. And visible deliverables that can solve the problem are produced based on sharing and collaboration, considering sociocultural context. Learners participate and collaborate with other learners in the NE-Maker class activities as a group, engage in making while considering the sociocultural context in a literary work, share a deliverable made with colleagues, and improve the deliverable to complete the task. In addition, the NE-Maker instructional model is differentiated from maker education, which motivates a learner simply through book stories, by presenting a newly written story by a learner as a form of deliverable along with the visible deliverable. This makes a learner think about the social effect that may be affected by the deliverable. In addition, the NE-Maker instructional model can lower the barrier to enter making education for students in a rural region, who are not accustomed to making activities, by replacing the context of real-life problems with the relatively simple context of a book (McCormick, 2015; Milto et al., 2020). 
The purpose of NE-Maker is to integrate and conceptualize the advantages of maker education (Cohen et al., 2018; Kang \& Yoon, 2017a; Hatch, 2014; Martin, 2015; Regalla, 2016; Yoon, 2018) that produces visible deliverables based on sharing and collaboration with novel engineering (Kim \& Lee, 2020; McCormick, 2015; Milto et al., 2020; Montgomery \& Madden, 2019; Novel Engineering, n.d.) in which a learner solves a problem of character in a book, and with project-based design thinking (Clapp et al., 2016; Clapp et al., 2020; Cohen et al., 2017; Drew, 2019; Agency by design, n.d.; Institute of Design at Stanford, 2020; Kapur, 2016) that produces deliverables for problem-solving by means of empathizing with customers. This study contains the novelty of combining three paradigms (Kim et al., 2020), which has not been previously attempted, even though they have a lot in common. This study proposes this model as a useful class model for real schools.

Fourth, this study aims to improve the sustainability of maker education through convergence. There is a concern that existing maker education was a limited and one-off form of education, and one-off educational models cannot support the unique characteristics of a maker education (Blikstein, 2013; Kim, 2018). Thus, this study aims to strengthen the cyclic and repetitive characteristics of making by fusing reading education and maker education, which are conducted iteratively, through proposing the NE-Maker instructional model (Hong \& Cho, 2019; Kim \& Lee, 2020). Significantly, the integration of literacy education with other fields can improve not only literacy but also learning in other fields (Grant et al., 2008; Halladay \& Neumann, 2012; Morrow et al., 1997) and can substitute the real-life scenarios of maker education with more accessible scenarios in a book's narrative, thereby lowering the entry obstacles to making (Mccormick, 2015; Milto et al., 2020). In addition, it is meaningful to propose a method of repetitive maker education so that the scope of maker education can be expanded into various fields available in the content books, which furthers the convergence approach (Kim et al., 2020).

\section{Conclusions}

The NE-Maker instructional model developed in this study fused the advantages of maker education, novel engineering, and design thinking and structured them into a process that can be applied to real classes. As a result, the "explore and empathize" and "rewrite the story" steps are distinct from the instructional model of general maker education. Accordingly, problems are discovered through active empathy within the rich context of books, and this can facilitate problem-solving by means of various tools and materials as well as the possibility of raising the maker's mindset through related activities. Since the NE-Maker instructional model aims to produce deliverables that can solve problems in the context of a book, interdisciplinary maker education that fuses various subjects in addition to engineering or literacy class can be employed to enable continuous and repetitive maker education by changing fusion subjects. Suggestions for future studies based on the present study's findings follow.

First, the subjects the NE-Maker instructional model must be diversified for grade year, school class, school and class size, and class form. In this study, 6th-grade 
elementary students in rural area were targeted to apply the developed NE-Maker instructional model, and the effects were investigated. Since NE is the educational method targeting elementary and middle school students (Milto et al., 2020), the model needs to be applied to not only upper-grade elementary students but also to lower-grade elementary and middle school students to confirm its effectiveness. In addition, diversifying the model's activities or structure would serve to determine whether the model is effective in different scenarios.

Second, the development of a concrete evaluation tool suitable to the NE-Maker instructional model is needed. This study employed the maker mindset testing tool (Kim \& Lee, 2020), which was developed previously, to measure educational effectiveness. However, a method of evaluation that is suitable for our model needs to be newly redefined considering that the NE-Maker has a different context and purpose from that of existing maker education models. Thus, it is necessary to conduct research on the development of evaluation tools after passing through the procedures that ensure the concrete reliability and validity of the model based on the process and results of this study to evaluate learners within a class that incorporates the NE-Maker instructional model.

Third, studies on the reduction of the ICT education gap between urban and rural students need to be conducted continuously. With the emergence of the Fourth Industrial Revolution, the need for ICT education for students has steadily increased, but the opportunity has been more concentrated in urban areas for urban students (Ainley, 2006; Chandra et al., 2021; Kim et al., 2014; Lembani et al., 2020; Liao \& Chang, 2010; Umar \& Jalil, 2012). To achieve SDG 4 by providing high quality education equally for all persons by all nations around the world by 2030, it is necessary to adopt a proactive approach to provide educational opportunity at the government level of each nation (United Nations, 2015). In particular, it is very important for students who will lead in the future to learn ICT, a key technology. To that end, it is crucial to ensure that all students have an opportunity to learn ICT without discrimination according to different external environments. Thus, it is critical to provide continuous research and policy on related themes, and based on this, we can go one step further in advancing toward a sustainable society.

\section{Limitation}

Maker education requires preparations such as teaching aids or materials, and many situations require physical intervention from teachers, such as supplying teaching aids. Thus, this study targeted a school where students attended class in person as the field test target because it the method is most applicable to a class in the classroom. Note that the field test of the NE-Maker instructional model developed in this study was conducted in 6th-grade small classrooms in two elementary schools due to the COVID-19 pandemic. Only one class was open for the entire year, due to the characteristic of small schools, which is why the comparative study could not be performed with two or more classes in the same school. Thus, the comparative study was conducted with 6th-grade students in another small school. 
Funding information This work was supported by the National Research Foundation of Korea (NRF) grant funded by the Korea government (MSIT) (No. 2021R1G1A109330611).

\section{Declarations}

Conflicts of interest/competing interests The authors declare that they have no conflict of interest.

\section{References}

Ackermann, E. (2001). Piaget's constructivism, Papert's constructionism: What's the difference. Future of learning group publication, 5(3), 438.

Agency by design. (n.d.). Educator Resources. http://agencybydesign.org.s219538.gridserver.com/edres ources/

Ainley, J. F. (2006, November 30). National assessment program--ICT literacy years 6 \& 10 report, 2005. Ministerial Council on Education, Employment, Training and Youth Affairs (NJ1). https:// eric.ed.gov/?id=ED530360

Anderson, C. (2012). Makers: The new industrial revolution. Crown Business.

Ball, B. J. (2019). The double diamond: A universally accepted depiction of the design process. Design Council. https://www.designcouncil.org.uk/news-opinion/double-diamond-universally-accepteddepiction-design-process

Bevan, B., Gutwill, J. P., Petrich, M., \& Wilkinson, K. (2015). Learning through STEM-rich tinkering: Findings from a jointly negotiated research project taken up in practice. Science Education, 99(1), 98-120. https://doi.org/10.1002/sce.21151

Blikstein, P. (2013). Digital fabrication and 'making' in education. In J. Walter-Herrmann \& C. Büching (Eds.), FabLab (pp. 203-222). Transcript Verlag. https://doi.org/10.14361/transcript.9783839423 820.203

Bowler, L. (2014). Creativity through "maker" experiences and design thinking in the education of librarians. Knowledge Quest, 42(5), 58-61.

Carroll, M., Goldman, S., Britos, L., Koh, J., Royalty, A., \& Hornstein, M. (2010). Destination, imagination and the fires within: Design thinking in a middle school classroom. International Journal of Art \& Design Education, 29(1), 37-53. https://doi.org/10.1111/j.1476-8070.2010.01632.x

Chandra, S., Chang, A., Day, L., Liu, J., McBride, L., Mudalige, T., Weiss, D., \& Fazlullah, A. (2021). Closing the K-12 digital divide in the age of distance learning. Broadband Communities. https:// www.bbcmag.com/broadband-applications/closing-the-k-ndash-12-digital-divide-in-the-age-ofdistance-learning

Choi, E. (2019). A study on selection of books and a guidance plan for applying novel engineering- $A$ subject. automation equipment, "[Master's Thesis, Incheon National University]. RISS.

Clapp, E. P., Ross, J., Ryan, J. O., \& Tishman, S. (2016). Maker-centered learning: Empowering young people to shape their worlds. Jossey-Bass.

Clapp, E. P., Solis, S. L., Ho, C. K. N., \& Laguzza, K. (2020). Maker-centered learning playbook for early childhood education. Agency by Design.

Cohen, J., Jones, W. M., Smith, S., \& Calandra, B. (2017). Makification: Towards a framework for leveraging the maker movement in formal education. Journal of Educational Multimedia and Hypermedia, 26(3), 217-229.

Cohen, J. D., Margulieux, L., Renken, M., Johns, W. M., \& Smith, S. (2018). Measuring maker mindset: Establishing content validity with card sorting. In J. Kay, \& R. Luckin (Eds.), Rethinking learning in the digital age: Making the learning sciences count, 13th international conference of the learning sciences (ICLS) 2018 (pp. 1505-1506). International Society of the Learning Sciences. https://repos itory.isls.org//handle/1/703

Dougherty, D. (2012). The maker movement. Innovations: Technology, governance, globalization, 7(3), 11-14. https://www.muse.jhu.edu/article/499244

Dougherty, D. (2013). The maker mindset. In M. Honey, \& D. E. Kanter (Eds.), Design, make, play (pp. 7-11). Routledge. 
Dougherty, D., O’Reilly, T., \& Conrad, A. (2016). Free to make: How the maker movement is changing our schools, our jobs, and our minds. North Atlantic Books.

Drew, C. (2019). The double diamond, 15 years on... - Design council. Medium. https://medium.com/ design-council/the-double-diamond-15-years-on-8c7bc594610e

Dym, C. L., Agogino, A. M., Eris, O., Frey, D. D., \& Leifer, L. J. (2005). Engineering design thinking, teaching, and learning. Journal of Engineering Education, 94(1), 103-120. https://doi.org/10. 1002/j.2168-9830.2005.tb00832.x

EiE (2020). The Engineering design process. http://www.eie.org/overview/engineering-design-process

Elo, S., \& Kyngäs, H. (2008). The qualitative content analysis process. Journal of Advanced Nursing, 62(1), 107-115. https://doi.org/10.1111/j.1365-2648.2007.04569.x

Flores, C. (2016). From name tags to lasting artifacts: Fostering a culture of deep projects. In S. Martinez \& H. Pang (Eds.), Meaningful making: Projects and inspirations for fab labs and makerspaces (pp. 4-6). Constructing Modern Knowledge Press.

Grant, A., Hutchinson, K., Hornsby, D., \& Brooke, S. (2008). Creative pedagogies:"art-full" reading and writing. English Teaching: Practice and Critique, 7(1), 57-72.

Grant, J. S., \& Davis, L. L. (1997). Selection and use of content experts for instrument development. Research in Nursing \& Health, 20(3), 269-274. https://doi.org/10.1002/(sici)1098-240x(199706)20: $3<269$ ::aid-nur9>3.0.co;2-g

Halladay, J. L., \& Neumann, M. D. (2012). Connecting reading and mathematical strategies. The Reading Teacher, 65(7), 471-476. https://doi.org/10.1002/TRTR.01070

Hasso-Plattner-Institut. (n.d.). The six phases of the Design Thinking process. https://hpi.de/en/school-ofdesign-thinking/design-thinking/background/design-thinking-process.html

Hatch, M. (2014). The maker movement manifesto: Rules for innovation in the new world of crafters, hackers, and tinkerers. McGraw-Hill Education.

Hong, J. Y. (2019). Development and application of SW fusion safety education program applying novel engineering. Journal of the Korea Institute of Information and Communication Engineering, 23(2), 193-200. https://doi.org/10.6109/jkiice.2019.23.2.193

Hong, K. C., \& Cho, Y. S. (2019). A novel engineering and creative learning process based on constructionism. Journal of information and communication convergence engineering, 17(3), 213-220. https://doi.org/10.6109/jicce.2019.17.3.213

IDEO Design Thinking. (n.d.). Design Thinking Defined. https://designthinking.ideo.com

Institute of Design at Stanford. (n.d.). An introduction to design thinking process guide. https://web.stanf ord.edu/ mshanks/MichaelShanks/files/509554.pdf

Kalil, T. (2013). Have fun-learn something, do something, make something. In M. Honey \& D. Kanter (Eds.), Design, make, play (pp. 30-34). Routledge.

Kang, E. S. (2017). A study on the educational effects of the maker education outreach program: A case study focused on free semester activity. [doctoral dissertation, Kyung Hee University]. RISS.

Kang, E. S., \& Yoon, H. J. (2017a). Theoretical background of the maker education. In I. Kang, H. J. Yoon, \& J. W. Hwang (Eds.), Maker education (pp. 19-52). Naeha.

Kang, I., \& Yoon, H. J. (2017b). Exploring the evaluation framework of maker education. Journal of the Korea Contents Association, 17(11), 541-553. https://doi.org/10.5392/JKCA.2017.17.11.541

Kang, I., Yoon, H. J., Jung, D. A., \& Kang, E. S. (2019). The theory and practice of maker education. Naeha.

Kapur, M. (2016). Examining productive failure, productive success, unproductive failure, and unproductive success in learning. Educational PsySchologist, 51(2), 289-299. https://doi.org/10.1080/00461 520.2016.1155457

Kim, B. (2020a). Development and validation of the maker mindset. [Master's thesis, Sungkyunkwan University]. RISS.

Kim B. S. (2020b). The effect of novel engineering on reading skills, problem solving and engineering creativity. [Master's thesis, Korea National University of Education]. RISS.

Kim, H. S., Kil, H. J., \& Shin, A. (2014). An analysis of variables affecting the ICT literacy level of Korean elementary school students. Computers \& Education, 77, 29-38. https://doi.org/10.1016/j. compedu.2014.04.009

Kim, J. O. (2018). Development of an instructional model for maker-based STEAM education. [doctoral dissertation, Korea National University of Education]. RISS.

Kim, J. Y., \& Lee, T. W. (2020). A study on the novel engineering-based maker education. Proceedings of Korean computer education conference, 24(2), 211-215. 
Kim, J. Y., Chung, H., Jung, E. Y., Kim, J. O., \& Lee, T. W. (2020). Development and application of a novel engineering-based maker education course for pre-service teachers. Education Sciences, 10(5), 126. https://doi.org/10.3390/educsci10050126

Kim, S. (2019). Development and evaluation of home economics maker education program for high school students: Focusing on the contents of 'Hanbok and creative clothing'. [doctoral dissertation, Korea National University of Education]. RISS.

Kim, Y. (2016). Development of a flipped-learning instructional model based on activity theory for higher education. [doctoral dissertation, Chung-Ang University]. RISS.

Lawshe, C. H. (1975). A quantitative approach to content validity. Personnel Psychology, 28(4), 563575. https://doi.org/10.1111/j.1744-6570.1975.tb01393.x

Lawson, B. (2005). How designers think, fourth edition: The design process demystified (4th ed.). Architectural Press.

Lee, H. D. (2020). The development of maker education instructional model for elementary school based on social emotional learning. [doctoral dissertation, Pusan University]. RISS.

Lee, J. S., Chun, S. W., \& Kwon, J. E. (2019). The current state and activating strategies of Korea's maker movement: Focusing on the effect of maker community participation. Journal of digital convergence, 17(9), 349-359. Doi: https://doi.org/10.14400/JDC.2019.17.9.349.

Lembani, R., Gunter, A., Breines, M., \& Dalu, M. T. B. (2020). The same course, different access: The digital divide between urban and rural distance education students in South Africa. Journal of Geography in Higher Education, 44(1), 70-84. https://doi.org/10.1080/03098265.2019.16948 76

Lembcke, S., Pilgaard, M., Hjorth, M., de Ridder, J. B., \& Fibiger, J. (2018, June 18). Makerspaces in university colleges [Paper presentation]. FabLearn Europe 2018: Conference on creativity and making in education, Trondheim, Norway. doi: 10.1145/3213818.3213843.

Liao, C. H., \& Chang, H. S. (2010). Explore the influences to Taiwan students' information literacy with the urban-rural differences from the perspective of globalization. Procedia - Social and Behavioral Sciences, 2(2), 3866-3870. https://doi.org/10.1016/j.sbspro.2010.03.606

Loertscher, D. V. (2013). Makerspaces in the school library learning commons and the uTEC maker model. Teacher Librarian, 41(2), 48-51.

Maker Ed. (2015). Youth makerspace playbook. Maker Education Initiative.

Marshall, J. A., \& Harron, J.R. (2018). Making learners: A framework for evaluating making in STEM education. Interdiscplinary Journal of Problem-Based Learning, 12(2), 25-35. doi: 10.7771/1541-5015.1749.

Martin, L. (2015). The promise of the maker movement for education. Journal of Pre-College Engineering Education Research, 5(1), 30-39. https://doi.org/10.7771/2157-9288.1099

Martinez, S. L., \& Stager, G. S. (2013). Invent to learn: Making, tinkering, and engineering in the classroom. Constructing Modern Knowledge Press.

McCormick, M. (2015). Complex dynamics of student engagement in novel engineering design activities (publication no. 728520) [doctoral dissertation, Tufts University]. ProQuest Dissertations \& Theses Gradworks Database.

McCormick, M., \& Hynes, M. (2012, June 10-13). Engineering in a fictional world: Early findings from integrating engineering and literacy [Paper presentation]. 2012 ASEE Annual Conference \& Exposition, San Antonio, Texas, USA. doi: 10.18260/1-2--21307

Milto. E., Wendell, K., Watkins, J., David, H., Spencer, K., Portsmore, M., \& Rogers, C. (2016). Elementary school engineering for fictional clients in children's literature. In L. A. Annetta \& J. Minogue (Eds.), Connecting science and engineering education practices in meaningful ways (pp. 263-291). Springer. doi: 10.1007/978-3-319-16399-4_11.

Milto, E., Portsmore, M., Watkin, J., McCormick, M., \& Hynes, M. (2020). Novel engineering, K-8. NSTA Press.

Montgomery, S., \& Madden, L. (2019). Novel engineering: Integrating literacy and engineering design in fifth grade classroom. Science Activities, 56(1), 27-32.

Morrow, L. M., Pressley, M., Smith, J. K., \& Smith, M. (1997). The effect of a literature-based program integrated into literacy and science instruction with children from diverse backgrounds. Reading Research Quarterly, 32(1), 54-76. https://doi.org/10.1598/rrq.32.1.4

Niens, J., Richter-Beuschel, L., \& Bögeholz, S. (2020). Land-use and health issues in Malagasy primary education-A delphi study. Sustainability, 12(15), 6212. https://doi.org/10.3390/su121 56212

Novel Engineering (n.d.). What does NE look like?. https://www. novelengineering.org/. 
O'brien, S. M. (2016). Teachers in the making: An investigation of pre-service teacher experience in a maker faire setting, and the role of design thinking. [doctoral dissertation, University of California]. ProQuest dissertations publishing. https://www.proquest.com/dissertations-theses/teach ers-making-investigation-pre-service-teacher/docview/1867760132/se-2?accountid=39011.

Palinscar, A. S., \& Duke, N. K. (2004). The role of text and text-reader interactions in young children's reading development and achievement. The Elementary School Journal, 105(2), 183-197. https://doi.org/10.1086/428864

Papert, S. (2000). What's the big idea? Toward a pedagogy of idea power. IBM Systems Journal, 39(3), 720-729. https://doi.org/10.1147/sj.393.0720

Papert, S., \& Harel, I. (1991). Situating constructionism. Constructionism, 36(2), 1-11.

Portsmore, M., \& Milto, E. (2018). Novel engineering in early elementary classrooms. In L. English \& T. Moore (Eds.), early engineering learning (pp. 203-223), springer. doi: 10.1007/978-981-10-8621-2_10.

Portsmore, M. D. (2010). Exploring how experience with planning impacts first grade students' planning and solutions to engineering design problem [doctoral dissertation, Tufts University]. ProQuest Dissertations Publishing. https://www.proquest.com/dissertations-theses/exploring-howexperience-with-planning-impacts/docview/305228421/se-2?accountid=39011

Regalla, L. (2016). Developing a maker mindset. In K. Peppler, E. R. Halverson \& Y. B. Kafai YB (Eds.), Makeology (pp. 257-272), Routledge. doi: 10.4324/9781315726519.

Rha, I. J., \& Chung, H. M. (2001). Developing an action model for WBI design. Journal of educational technology, 17(2), 27-52. Doi: 10.17232/kset.17.2.27.

Richey, R. C., \& Klein, J. D. (2007). Design and development research. Routledge.

Riverdale \& IDEO (2014). Design Thinking for educators (2nd ed.). Riverdale \& IDEO.

Rodriguez, S., Allen, K., Harron, J., \& Qadri, S. A. (2019). Making and the 5E learning cycle. The Science Teacher, 086(05), 24-30. https://doi.org/10.2505/4/tst18_086_05_48

Roffey, T., Sverko, C., \& Therien, J. (2016, April 3). The making of a makerspace: Pedagogical and physical transformations of teaching and learning. Makerspace for Education. https://www.iteea. org/File.aspx $? \mathrm{id}=133027 \& \mathrm{v}=134 \mathrm{a} 6 \mathrm{~d} 62$

Roscoe, J. T. (1975). Fundamental research statistics for the behavioral sciences (2nd ed.). Holt, Rinehart and Winston.

Rubio, D. M., Berg-Weger, M., Tebb, S. S., Lee, E. S., \& Rauch, S. (2003). Objectifying content validity study in social work research. Social Work Research, 27(2), 94-104. https://doi.org/10. 1093/swr/27.2.94

Seo, H. J., \& Lee J.Y. (2018). Analysis of future education trends using semantic network analysis, Korean Association for Educational Information and Media, 24(4), 649-678. doi: 10.15833/ kafeiam.24.4.649

Smith, R. C., Iversen, O. S., \& Hjorth, M. (2015). Design thinking for digital fabrication in education. International Journal of Child-Computer Interaction, 5, 20-28. https://doi.org/10.1016/j. ijcci.2015.10.002

Stager, G. (2006). An investigation of constructionism in the Maine youth center. [doctoral dissertation, the University of Melbourne].

Teach engineering. (n.d.) Engineering design process. https://www.teachengineering.org/design/desig nprocess

The Interaction Design Foundation. (n.d.). What is Design Thinking? https://www.interaction-design. org/literature/topics/design-thinking

The White House Office of the Press Secretary (2015, June 15). Factsheet: New commitments in support of the president's nation of makers initiative. The white house president Barack Obama. https://obamawhitehouse.archives.gov/the-press-office/2015/06/12/fact-sheet-new-commitmentssupport-president $\%$ E $\% 80 \% 99$ s-nation-makers-initiative

Umar, I. N., \& Jalil, N. A. (2012). ICT skills, practices and barriers of its use among secondary school students. Procedia - Social and Behavioral Sciences, 46, 5672-5676. https://doi.org/10.1016/j. sbspro.2012.06.494

UNESCO (2017). Education for sustainable development goals: Learning objectives. http://unesdoc. unesco.org/images/0024/002474/247444e.pdf

United Nations (2015). Transforming our world: the 2030 agenda for sustainable development. https:// sdgs.un.org/2030agenda

Fried, B., \& Wetstone, K. (2014, June 18). The white house maker faire: “Today's D.I.Y. is Tomorrow's 'made in America'". The white house president Barack Obama. https://obamawhitehouse. 
archives.gov/blog/2014/06/18/president-obama-white-house-maker-faire-today-s-diy-tomorrows-made-america

Yoon, H. J. (2018). The development of a model of maker education utilizing design thinking. [doctoral dissertation, Kyung Hee University]. RISS.

Yoon, H. J., Kang, I., \& Kang, E. S. (2019). A case study of a maker education outreach program: Fostering maker mindsets. Journal of Educational Technology, 35(S), 365-393. doi: 10.17232/ KSET.35.2.365

Publisher's note Springer Nature remains neutral with regard to jurisdictional claims in published maps and institutional affiliations.

\section{Authors and Affiliations}

\section{Ji-Yun Kim ${ }^{1}\left(\mathbb{D} \cdot\right.$ Jae Seon $\mathrm{Seo}^{2} \cdot$ Kwihoon $\mathrm{Kim}^{3}$}

1 Department of Computer Education, Korea National University of Education, Cheongju, South Korea

2 Center for Apprentice High School, Korea Research Institute for Vocational Education and Training, Sejong, South Korea

3 Department of Artificial Intelligence Convergence Education, Korea National University of Education, Cheongju, South Korea 